\title{
Management of Congenital Toxoplasmosis
}

\author{
Rima McLeod • Joseph Lykins • A. Gwendolyn Noble $\cdot$ Peter Rabiah • \\ Charles N. Swisher - Peter T. Heydemann - David McLone - David Frim • \\ Shawn Withers · Fatima Clouser · Kenneth Boyer
}

Published online: 22 July 2014

(C) Springer Science + Business Media New York 2014

\begin{abstract}
Prompt diagnosis and rapid initiation of medical treatment are critical for the best outcomes in infants with congenital toxoplasmosis. This is important for pregnant women, fetuses, and infants, including those with active retinitis and choroidal neovascular membranes. For hydrocephalus, prompt placement of a ventriculoperitoneal shunt is key for improved outcomes. Pyrimethamine and Sulfadiazine with Leucovorin are first-line medicines. For later recurrences of active retinitis, Azithromycin or Clindamycin are sometimes substituted for Sulfadiazine as
\end{abstract}

\footnotetext{
R. McLeod $(\bowtie)$

Department of Ophthalmology and Visual Science, Pediatrics (Infectious Diseases), Committees on Immunology, Molecular Medicine, Global Health, Institute Genomics, Genetics and Systems Biology, and The College, The University of Chicago, 5841 S. Maryland Avenue, Room N-310, MC 2114, Chicago, IL 60637, USA

e-mail: rmcleod@bsd.uchicago.edu

J. Lykins

Pritzker School of Medicine, The University of Chicago, 5841 S. Maryland Avenue, Room N-310, MC 2114, Chicago, IL 60637, USA

e-mail: lykinsj@uchicago.edu
}

A. Gwendolyn Noble $\cdot$ C. N. Swisher - D. McLone

Lurie Children's Hospital and Northwestern University, 225 E.

Chicago Avenue, Chicago, IL 60611, USA

e-mail: agnoble@ameritech.net

C. N. Swisher

e-mail: cswisher@luriechildrens.org

D. McLone

e-mail: dmclone@aol.com

P. Rabiah

NorthShore University Health System, 9650 Gross Point Rd.,

Suite 1900, Skokie, IL 60076, USA second-line treatments, given with Pyramethamine. Following resolution of active retinitis, these medicines may be useful without Pyrimethamine for suppression and avoid the risk of hypersensitivity from Trimethoprim/Sulfamethoxazole. Antibody to VEGF, in conjunction with antimicrobial therapy, results in resolution of choroidal neovascular membranes. Serologic screening of seronegative pregnant women to detect primary infection during gestation, and facilitating medicine administration and thereby preventing or treating fetal infection, is an optimal,

\section{P. T. Heydemann}

Rush University Medical Center, 1725 W. Harrison ST., Suite

710, Chicago, IL 60612, USA

e-mail: peter_heydemann@rush.edu

D. Frim

Department of Neurosurgery, The University of Chicago, 5841

S. Maryland Avenue, MC 3026, Chicago, IL 60637, USA

e-mail: dfrim@surgery.bsd.uchicago.edu

\section{S. Withers · F. Clouser}

Department of Opthalmology and Visual Science, Pediatrics

(Infectious Diseases), The University of Chicago, $5841 \mathrm{~S}$.

Maryland Avenue, Room N-310, MC 2114, Chicago, IL 60637,

USA

e-mail: shawnwithers@aol.com

F. Clouser

e-mail: falibana@uchicago.edu

\section{K. Boyer}

Rush University Medical Center, 1653 W. Congress Pkwy, 770

Jones, Chicago, IL 60612, USA

e-mail: kboyer@rush.edu 
apparently cost-effective, means to reduce disease. Definitively curative medicines currently being developed likely will improve future management and outcomes of this disease.

Keywords Congenital toxoplasmosis - Toxoplasma gondii · Improved outcomes · Treatment - Gestational screening $\cdot$ Newborn toxoplasmosis managment

\section{Introduction}

In 1939, Wolf and Cowen reported the first case of congenital toxoplasmosis attributed to Toxoplasma gondii [1]. This infected infant presented with ultimately fatal encephalitis [1] and was diagnosed with $T$. gondii infection by Sabin [2]. Other cases were described in the following years. Understanding of clinical manifestations, pathogenesis, pathology, and development of current approaches to optimal management evolved over the next decades [3, 4,

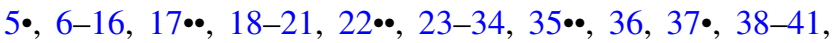
42••, 43-47, 48•, 49-62, 63•, 64-67, 68•, 69. 70•, 71-78, $79 \bullet \bullet, 80 \bullet \bullet, 81 \bullet \bullet, 82 \bullet, 83,84 \bullet, 85 \bullet, 86,87 \bullet, 88-90,91 \bullet, 92$, 93, 94••, 95, 96, 97•, 98••, 99-111, 112•, 113•114-118, $119 \bullet, 207]$. In the 1950s and 1960s, the severity of infection was recognized to be inversely correlated with gestational age at the time of infection. Transmission rates were low early in gestation but were associated with more severe clinical disease, while transmission occurred more frequently later in gestation but was frequently subclinical [23-30, 36-40, 43, 44, 63•, 64]. Prognosis was guarded for those infants with substantial manifestations of active disease at birth in the absence of subsequent treatment [43, 44]. Untreated subclinical infections were noted to harm children later in life, particularly causing cognitive decline and recurrent retinal disease [63•,64]. The presence of meningitis or retinal disease was noted in up to $50 \%$ of infants whose infection went unnoticed with standard newborn examinations. In France, Austria, and Germany, gestational serologic screening programs were developed to detect acquisition of infection during fetal life [21, 28, $31,49,61,62,115,117,118]$. Treatment to prevent infection and disease in the fetus and infant was optimized (Fig. 1; [21, 28, 31, 49, 61, 62, 69, 70•, 71-78, 79••, 80••, $81 \bullet \bullet, 107,115-118], 119 \bullet, 120 \bullet, 121 \bullet \bullet, 207)$. In a phase 1 study and in a phase 2 randomized trial of a higher and lower dosage of Pyrimethamine treatment of infants compared with untreated historical controls (Fig. 2), and treated children with recurrent eye disease had improved outcomes [35, 69, 70• 71-78, 79••, 80••, 81••, 92, 93, 114, $121 \bullet \cdot, 207]$. Effective treatments in infancy and through the first year of life were defined in the USA, and this work changed the approach to management of the disease in the
Fig. 1 Gestational screening and treatment to improve outcomes. a Serologic screening for $T$. gondii infection during pregnancy an algorithm for early diagnosis of acquisition of $T$. gondii infection. For boxes shaded with blue, consult with high-risk maternal-fetal medicine. Adapted with permission from McLeod et al. [206, 207]. b Screening for toxoplasmosis throughout pregnancy. Diagram indicating when and how screening for $T$. gondii infection should occur, prenatally and 1 month after birth. Adapted with permission from McLeod et al. [206, 207]. c Amniocentesis to Detect Congenital $T$. gondii Infection. Relationship between percentage of pregnant women undergoing amniocentesis (open bars) and those with fetuses with congenital toxoplasmosis (filled bars) as a function of the gestational age at seroconversion. The inserted table indicates the sensitivity, specificity, and positive and negative predictive values of PCR analysis of samples obtained via amniocentesis as a function of trimester. Adapted with permission from Wallon et al. [119]. d Gestational age and its relationship to parasitemia. Relationship between the gestational age at the time of maternal infection with $T$. gondii and the magnitude of parasitemia (parasites $/ \mathrm{mL}$ ). Note early infection is correlated with more severe disease. Empty bars are indicative of subclinical infection, while filled bars represent symptomatic infection. Adapted with permission from Romand et al. [103]. e French algorithm and its impact on outcomes in congenital toxoplasmosis. Summary of outcomes for congenitally infected individuals. Adapted with permission from Mehta et al. [208]. f Impact of the french approach on likelihood of congenital infection with $T$. gondii. Impact of utilization of French algorithm on probability of fetal infection following gestational infection as a function of gestational age. In the Lyon Cohort, this approach to early screening/treatment was implemented in 1992, and, at that time, probability of fetal infection decreased. Accompanying table indicates both reduction in the risk of infection and of clinical signs of congenital Toxoplasma infection following changes in screening policy in 1992 and prenatal diagnosis and treatment in 1995. Adapted with permission from Wallon et al. [120]. $\mathbf{g}$ Impact of early detection/ treatment on frequency of eye disease at 3 years of age. KaplanMeier plot depicting the impact of early diagnosis and treatment on the fraction of patients without eye disease. In patients with less than 4 weeks of delay between gestational infection and initiation of treatment (solid line) and with between four and 8 weeks of delay (dashed line), eye disease is much less common than for those patients with an interval of greater than eight weeks between infection and treatment (dotted line). Adapted with permission from Kieffer et al. [62]. h Conclusions regarding the outcomes of $T$. gondii infection in those infants with prenatal screening, diagnosis, and treatment. Adapted with permission from and McLeod et al. [207]. (I) - A Time and Treatment of $T$. gondii Infection Adapted with permission from McLeod et al. [206, 207]. (I) -B Effect of treatment on quality of life in congenital $T$. gondii infection impact of treatment within a study cohort on various measures of quality of life. Adapted with permission from McLeod et al. [206, 207]. (I) - C. Frequency of ophthalmologic and neurologic manifestations of congenital toxoplasmosis. Frequency of symptoms, especially ophthalmologic and neurologic symptoms, within a study cohort of patients with congenital T. gondii infection. Adapted with permission from McLeod et al. [206, 207]

next decades in the USA $[69,70 \bullet, 71-78,79 \bullet \bullet, 80 \bullet \bullet, 81 \bullet \bullet$, $121 \bullet \bullet, 207]$, as well as in France, Austria, Germany, and

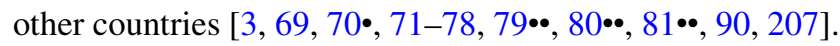
Mathematical analyses suggest that such serologic screening will be cost-effective in the USA, and these methods of analysis are also being applied in other countries such as 


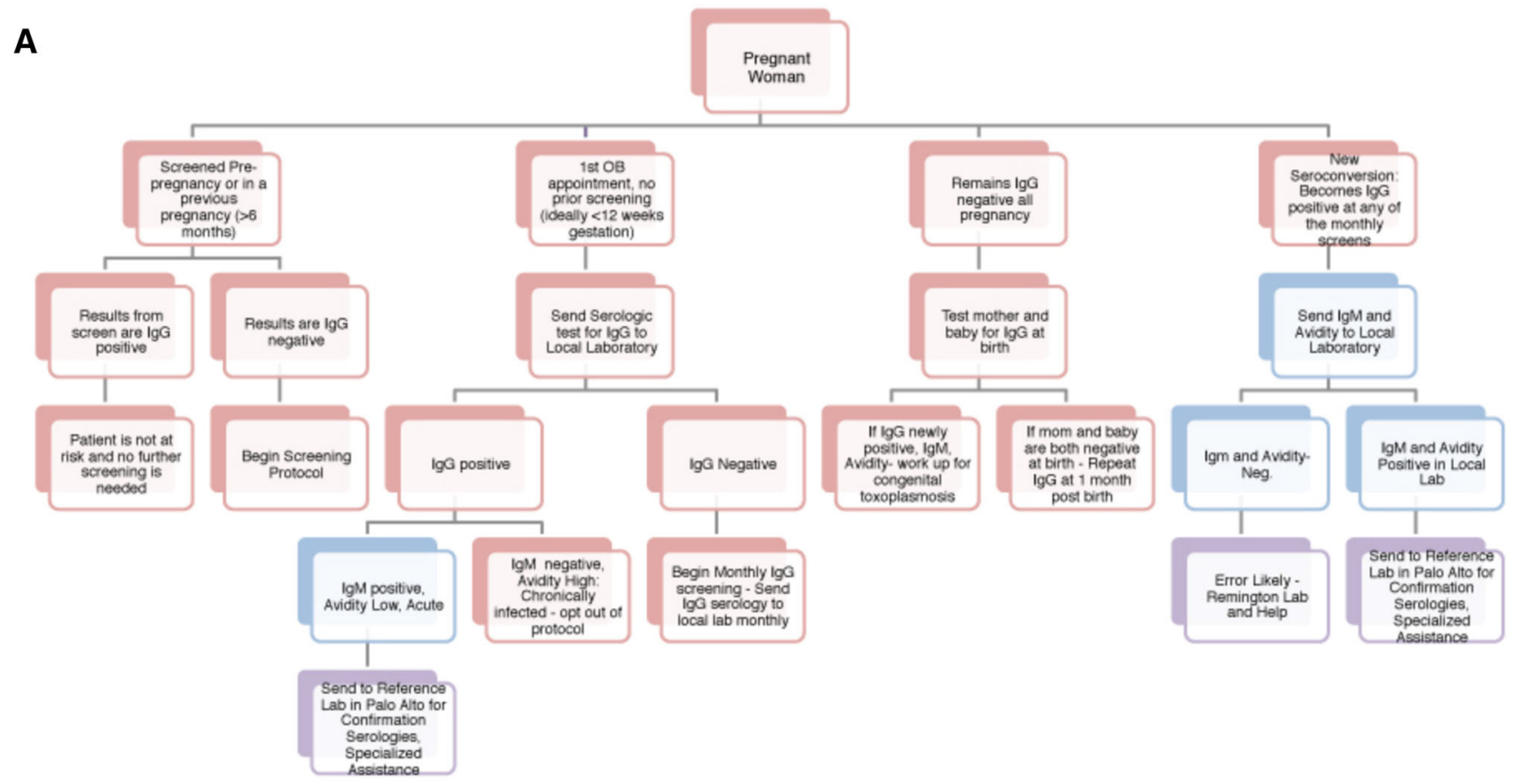

B Pre-
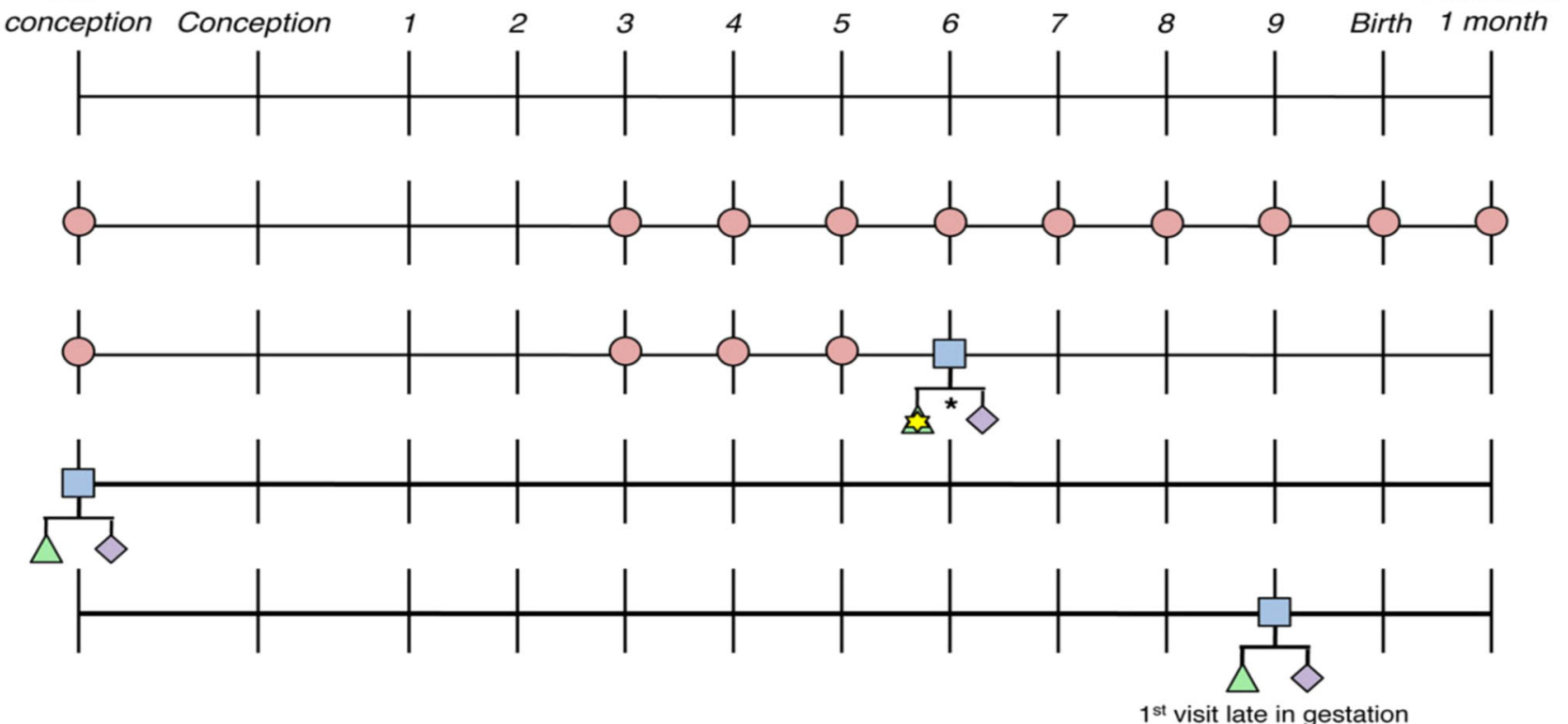

\begin{tabular}{|c|l|}
\hline$\bigcirc$ & IgG - \\
\hline$\square$ & IgG + \\
\hline$\triangle$ & $\begin{array}{l}\text { Chronic: No IgM when } 1{ }^{\text {st }} \text { IgG checked, avidity high. No opportunity to } \\
\text { observe when seroconverted }\end{array}$ \\
\hline$\diamond$ & Acute with IgM+, reference lab, fetal-maternal high risk, help \\
\hline$\star$ & This could happen at any time along timeline \\
\hline$\Sigma$ & Seroconverted with M: something is wrong in this (lab error), get help \\
\hline
\end{tabular}

$1^{\text {st }}$ visit late in gestation

Brazil and Panama. Adjunctive treatments such as prompt ventriculoperitoneal shunt procedures resulted in favorable outcomes for some infants with hydrocephalus.
Without such medical and neurosurgical interventions, prognosis is guarded $(96,119$, Hutson, McLeod, et al. in preparation). Herein, we present practical approaches to 
C

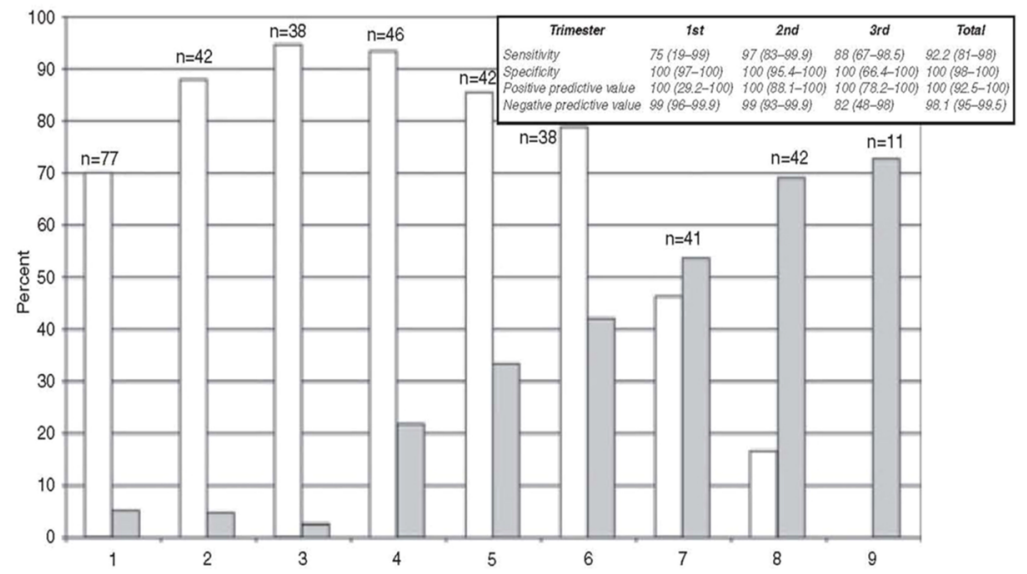

D

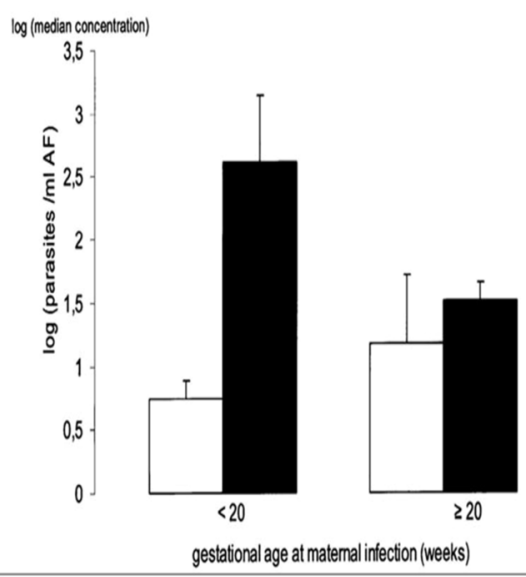

E

\begin{tabular}{|c|}
\hline Outcomes Using the French Algorithm \\
\hline - Diagnose Mother: Systematic serologic screening before conception, intrapartum, and postpartum. \\
\hline $\begin{array}{l}\text { - Treat Mother: If acute serology, spiramycin reduces transmission of } T \text {. gondii across placenta to fetus, but does not treat the fetus. } \\
\text { • Untreated } 94(60 \%) \text { of } 154 \text { vs. treated } 91(23 \%) \text { of } 388^{2} \text {. }\end{array}$ \\
\hline $\begin{array}{l}\text { - Diagnose Fetus: Ultrasounds, amniocentesis, PCR at } \geq 18 \text { wk gestation }{ }^{b} \text {. } \\
\text { - Sensitivity } 37(97 \%) \text { of } 38 \text {; specificity } 301 \text { of } 301^{c} \text {. For mid-gestation infections, please see Figure } 2 .\end{array}$ \\
\hline - Treat Fetus: Treat mother with pyrimethamine and sulfadiazine, which cross the placenta to treat the fetus. \\
\hline $\begin{array}{l}\text { - Hohlfeld, } \text { : } \mathrm{N}=54 \text { live births; } 34 \text { terminations; All } 54 \text { normal development. } 19 \% \text { subtle findings: } 7(13 \%) \text { intracranial calcifications, } 3(6 \%) \text { chorioretinal scars. } \\
\text { Follow-up of } 18 \text { children (median age } 4.5 \mathrm{yr} \text {; range } 1-11 \mathrm{yr} \text { ): } 39 \% \text { retinal scars, most scars were peripheral. }\end{array}$ \\
\hline $\begin{array}{l}\text { - Couveure: Compared to a spiramycin regimen, adding pyrimethamine and sulfadiazine to a spiramycin regimen reduce the number of isolates from placenta } \\
\text { from } 77 \% \text { to } 42 \% \text {, reduced } T \text {. gondii-specific immunoglobulin load at birth from } 139 \mathrm{IU} / \mathrm{g} \mathrm{IgG} \text { to } 86 \mathrm{IU} / \mathrm{g} \mathrm{IgG} \text { and at } 6 \mathrm{mo} \text {. from } 137 \mathrm{IU} / \mathrm{g} \mathrm{IgG} \text { to } 70 \mathrm{IU} / \mathrm{g} \mathrm{IgG} \text {, } \\
\text { reduced } T \text {. gondii-specific IgM prevalence in the neonate from } 69 \% \text { to } 17 \% \text {, and increased subclinical infections, presumably by delaying transmission, from } \\
17 \% \text { to } 30 \% \text {. }\end{array}$ \\
\hline - Kieffer: Shorter interval between diagnosis and treatment reduces subsequent retinal disease. \\
\hline - Syrocots: Shorter interval between diagnosis and treatment reduces subsequent neurologic disease. \\
\hline - Conclusion: Favorable outcomes with treatment in utero in France and as French Algorithm applied in U.S.h.i. \\
\hline
\end{tabular}

$\mathbf{F}$

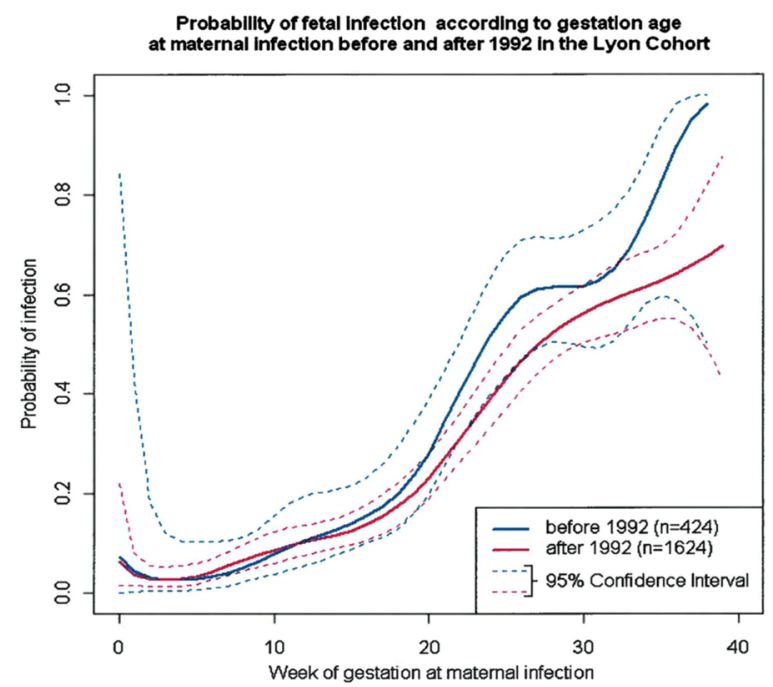

Reduction in the risk of infection and of clinical signs following changes in the retesting policy (1992) and in antenatal diagnosis and treatment procedures (1995) (Lyon-Cohort)

\begin{tabular}{|c|c|c|c|c|}
\hline Periods & $1987-1991$ & 1992-1995 & $1996-2008$ & \\
\hline \multicolumn{5}{|l|}{ Risk of Infection } \\
\hline $\begin{array}{l}\text { Retesting policy for women } \\
\text { identified as susceptible at the first } \\
\text { prenatal test implemented in } 1985\end{array}$ & $\begin{array}{l}\text { Recommended } \\
\text { without specific } \\
\text { frequency }\end{array}$ & \multicolumn{2}{|c|}{ Mandatory and monthly } & \\
\hline Infected children/mothers & $125 / 424$ & \multicolumn{2}{|l|}{$388 / 1,624$} & $P<0.018$ \\
\hline \multicolumn{5}{|l|}{ Risk of clinical signs at age 3 years } \\
\hline PCR availability on amniotic fluid & No & & Yes & \\
\hline PS antenatal treatment & \multicolumn{2}{|c|}{$\begin{array}{l}\text { Alternating with spiramycin for } 3 \text { - } \\
\text { week periods }\end{array}$} & Continuous & \\
\hline Clinical signs/infected children & $87 / 794$ & & $46 / 1,150$ & $P<10^{-4}$ \\
\hline
\end{tabular}

Fig. 1 continued

manage this infection to optimize the quality of life for infected individuals and their families [78, 79••]. The more rapidly the diagnosis is made, with prompt initiation of treatment, the better the observed outcome.

\section{Prevention, Diagnosis, and Treatment of Congenital Toxoplasmosis During Gestation}

Optimal management of congenital $T$. gondii infection begins with prenatal diagnosis, prevention of transmission to 


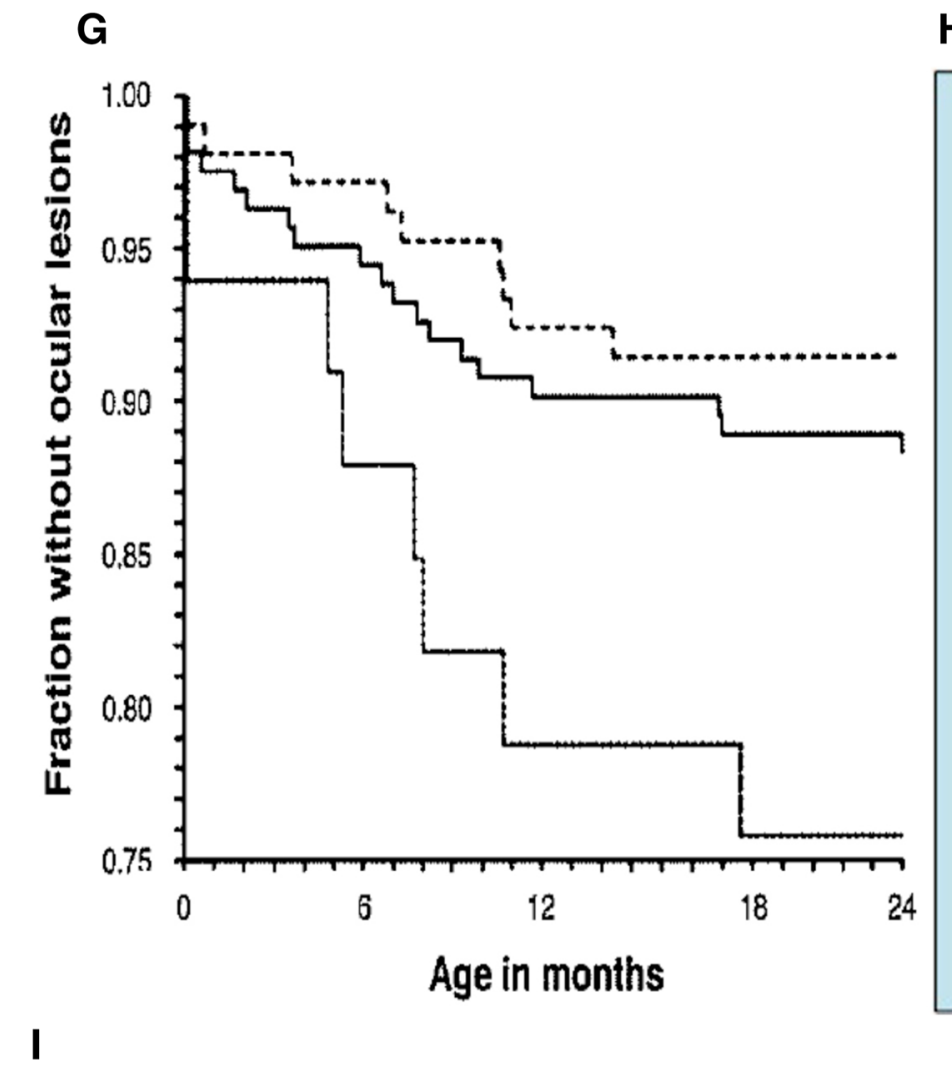

H

\section{Conclusions:}

- Gestational age of $T$. gondii infection acquisition predicts maternal-fetal transmission

-Delay in prenatal treatment increases the risk of clinical signs in infected children

-Prenatal treatment results in:

-Decreased number of cases with severe infection

-Decreased number of cases with mild infection

- Decreased incidence of sequelae at birth

- Decreased number of late sequelae

-Decreased incidence of vertical transmission

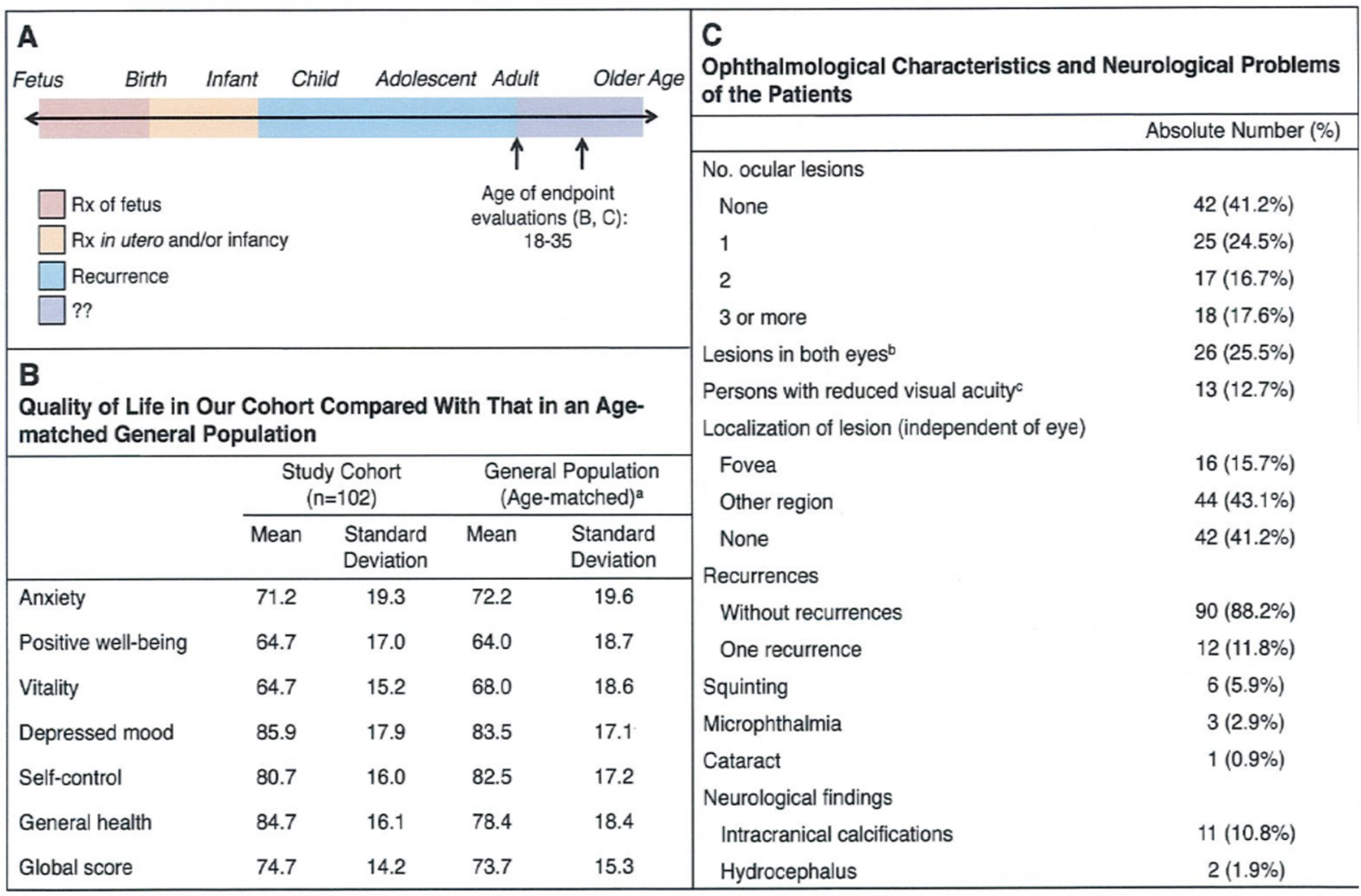

Fig. 1 continued 


\section{A-1}

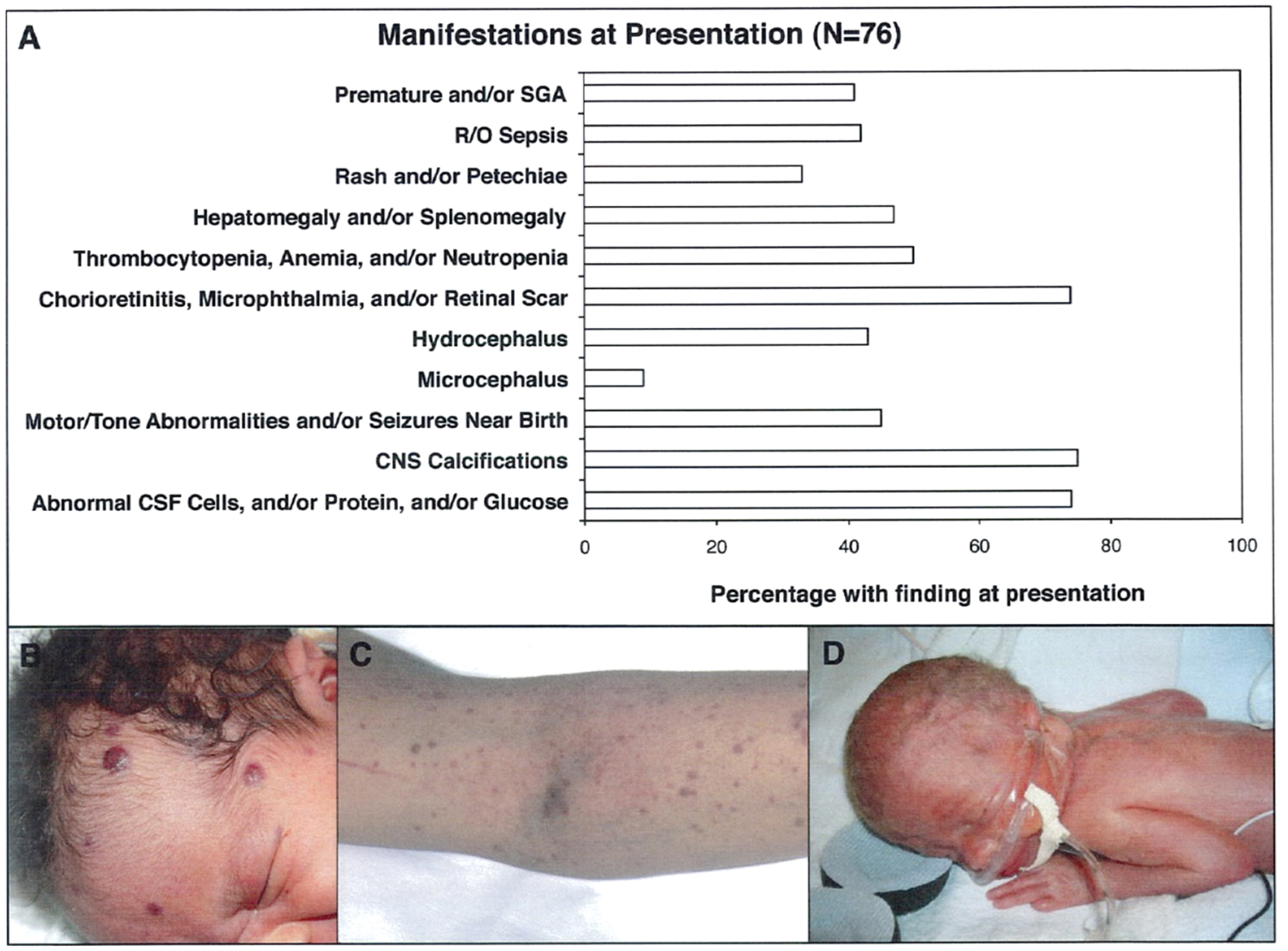

Fig. 2 Manifestations of congenital toxoplasmosis in infancy. a A1Percentage of patients with specific manifestations of congenital $T$. gondii infection with several images of some of these manifestations. These include blueberry muffin rash (in this case, with congenital infection with cytomegalovirus, though the manifestation is the same in congenital toxoplasmosis), petechiae secondary to thrombocytopenia, and an infant born, prematurely, as a result of $T$. gondii infection. Adapted with permission from McLeod et al. [206, 207]. Data from McAuley et al. [71]. Image from Mehta et al. [208] and from http://www.nhlbi.nih.gov/health/health-topics/topics/itp/ with permission. A2-Approach and samples for the diagnosis of congenital T. gondii Infection. Diagnostic approaches to congenital toxoplasmosis in a newborn, including specific instructions regarding samples, shipment, and diagnostic procedures. Adapted with permission from McLeod et al. [206, 207]. b Ordering serologic testing for $T$. gondii

the fetus, and treatment of the fetus as soon after acquisition as possible $[3,4,5 \bullet, 6-16,17 \bullet \bullet, 18-21,22 \bullet \bullet, 23-34,35 \bullet \bullet, 36$, 37•, 38-41, 42••, 43-47, 48•, 49-62, 63•, 64-67, 68•, 69. 70•,

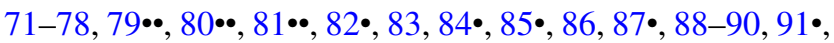
92, 93, 94••, 95, 96, 97•, 98••, 99-111, 112•, 113•114-118, 119•, 120••, 207]. This approach was developed in France (Fig. 1) and is currently the gold standard of care for all pregnant women in that country. Preconception or serologic screening by 11 weeks identifies seronegative women who undergo monthly serologic screening for $T$. gondii $\mathrm{IgG}$ and IgM beginning at 11 weeks' gestation and continuing from the U.S. Reference laboratory. An example of a completed order form for serological testing from a typical reference laboratory in order to diagnose a patient with suspected congenital infection with $T$. gondii. Adapted with permission from McLeod et al. [206, 207]. c Diagnostic testing for $T$. gondii Infection organized by sample type. Examples of the types of testing that can be used to diagnose congenital toxoplasmosis as a function of sample type. Adapted with permission from McLeod et al. [206, 207]. d Geography, genetic diversity, and disease manifestations in the U.S. T. gondii Population. Relationship between geography, genetic diversity, and disease manifestation in $T$. gondii in the Uni. Note the prevalence of different serotypes depending upon region, as well as the impact of genotype on severity. Genotype also shows some co-association with a variety of epidemiological factors. Adapted with permission from McLeod et al. [79]

through the first postpartum month. This approach identifies gestational infection in the previously seronegative pregnant woman by detecting the presence of new $T$. gondii-specific serum antibody. When a pregnant woman seroconverts, treatment with Spiramycin, which is concentrated in the placenta, can block transmission to the fetus up to $50 \%$ of the time [95]. This approach is used for maternal infection prior to the 17th week of gestation without known transmission to the fetus. Further therapy is stratified based on the presence or absence of fetal infection; amniocentesis with PCR for $T$. gondii DNA is utilized to diagnose fetal infection 
A-2

A

\section{NARRATIVE FOR DIAGNOSIS OF CONGENITAL TOXOPLAMOSIS IN NEWBORN INFANT}

I) SAMPLES OBTAINED IN DELIVERY ROOM
This includes: Placenta to go to reference laboratory for A-subinoculation into
mice and B-PCR. Amniotic fluid, if available

A. 200 gram sample of placenta from the cord insertion area on the fetal side (100 gram is approximately $14 \mathrm{~cm} \times 3 \mathrm{~cm} \times 3 \mathrm{~cm})$ for subinoculation into mice and PCR.

1. Storage

Store sterilely in sterile saline (NO FORMALIN OR OTHER PRESERVATIVE, DO NOT FREEZE). Penicillin (100 units per $\mathrm{mL}$ ) and Streptomycin $(100 \mu \mathrm{gm} / \mathrm{mL})$ or gentamicin to laboratory capable of subinoculation should be added. Keep placenta cool (NOT FROZEN) with ice bag or preferably frozen cold packs.

2. Shipping

Ship immediately (ASAP) by Federal Express.

The US Reference Laboratory Address:

Research Institute

Palo Alto Medical Foundation

Attn: Serology

Ames Building

795 El Camino Real Palo Alto, CA 94301

(650) 853-4828

Call receiving laboratory when the placenta is obtained so proper handling upon receipt is assured. Note that samples for subinoculation must be received within 72 hours of collection.

European Laboratory, where available:

Contact Herve Pelloux

HPelloux@chu-grenoble.fr

B. 10-20 mL (or more) amniotic fluid, if available (for PCR of pellet

and subinoculation). Not essential if obtained early.

1. Storage and shipping

Keep cold (NOT FROZEN) and ship with sample I(A) as described above.

Each sample for PCR should be placed in a separate sealed bag to prevent cross-contamination. To be centrifuged by Reference Laboratory.

\section{II) CLINICAL EXAMINATIONS AND EVALUATIONS OF BABY}

FOLLOWING BIRTH

A. General Examination

B. Pediatric Ophthalmologist

C. Pediatric Neurologist

D. CT scan of the brain. Baby should not be sedated and may be gently swaddled. This examination is done without contrast. Examine for ventricular size and brain calcifications.

E. Auditory Acoustic Emissions or BAER (hearing test) Currently Available Test in French and American Reference Laboratories.

\section{III) SAMPLES OBTAINED FROM INFANT SUBSEQUENT TO DELIVERY} AT DELIVERING HOSPITAL

The following samples and tests are obtained for the newborn infant and processed and analyzed at the delivering hospital.

1. СВС with differential and platelet count

2. Serum: total IgM, IgG, IgA, albumin

3. Serum: SGPT, SGOT, total and direct bilirubin, creatinine

4. Urinalysis

5. Lumbar puncture

a) Cerebrospinal fluid: cell count, glucose protein and total IgG. b) Please note that an additional $0.5 \mathrm{~mL}$ is to be collected for $\mathrm{lgG}$ and IgM specific for $T$. gondii to be sent to a reference lab such as Palo Alto Medical Foundation as described below in "IV) 3." c) If available, hold $1.5 \mathrm{~mL}$ frozen cerebrospinal fluid for quantitative $\mathrm{lgG}$ if needed later to calculate antibody load $(0.5 \mathrm{~mL})$ and pcr $(1.0 \mathrm{~mL})$. Place $0.5 \mathrm{~mL}$ and $1.0 \mathrm{~mL}$ in separate tubes.
IV) The following samples are to be sent to a reference lab such as Palo Alto Medical Foundation (address above). They should be kept cold (NOT FROZEN). Remember to include the permission form for the PAMF to release serologic and isolation results to the Toxoplasmosis Research Institute and Center / Dr.McLeod. Note that these may be stored and shipped with sample I(A) described above.

1. $2 \mathrm{~mL}$ sterile infant peripheral blood

This is peripheral blood (i.e. not umbilical cord blood)

Place in two purple top tubes of $1 \mathrm{~mL}$ each.

This is for PCR and subinoculation of buffy coat. Also send sterile clot from "2" below.

2. $1 \mathrm{~mL}$ serum

This is for the Toxoplasma Baby Panel: Sabin Feldman Dye test, IgM ISAGA, IgA ELISA. Clot below this sample. See "IV) 1."

3. $0.5 \mathrm{~mL}$ cerebrospinal fluid This is for T.gondii specific IgG (dye test) and IgM ELISA. (See "III) 5" above.)

4. 5 cc urine - Investigational. Not proven sensitivity. For PCR.

V) SAMPLES OBTAINED FROM MOTHER SUBSEQUENT TO DELIVERY

\section{2 mL Maternal Serum}

Adult panel to go to a reference laboratory such as Palo Alto Medica Foundation (address above) with I) A and IV).

To be used for IgG in parallel with infant IgG test and cab ne used for $\lg M$ and $\lg A$ if clinically indicated.

VI) Amounts, Handling, and Shipping of T. gondil-specific Tests and Samples Table. Currently available tests in US or France Reference Laboratories.

\begin{tabular}{|c|c|c|c|c|}
\hline Test & Sample & $\begin{array}{c}\text { Preferred } \\
\text { (Min. Amount) }\end{array}$ & Store/Ship & $\begin{array}{l}\text { Additional } \\
\text { Comments }\end{array}$ \\
\hline Dye Test IgG & Seruma & $\begin{array}{c}0.25 \mathrm{~mL} \\
(0.050 \mathrm{~mL})\end{array}$ & $\mathrm{CoOl}^{\circ}$ & \\
\hline \multirow{2}{*}{$\begin{array}{l}\text { Direct } \\
\text { Agglutination lgG } \\
\text { IgM ELISA }\end{array}$} & Serum & $0.25 \mathrm{~mL}$ & Cool & \\
\hline & Serum & $0.25 \mathrm{~mL}$ & Cool & \\
\hline IgM ISAGA & Serum & $0.25 \mathrm{~mL}$ & Cool & \multirow[t]{2}{*}{$\begin{array}{c}\text { Only for } \\
\text { babies<6 months }\end{array}$} \\
\hline IgA ELISA & Serum & $0.25 \mathrm{~mL}$ & Cool & \\
\hline IgE ELISA & Serum & $0.25 \mathrm{~mL}$ & Cool & $\begin{array}{l}\text { Limited clinical } \\
\text { use }\end{array}$ \\
\hline $\mathrm{AC} / \mathrm{HS}$ & Serum & $0.25 \mathrm{~mL}$ & Cool & $\begin{array}{l}\text { For pregnant } \\
\text { woman }\end{array}$ \\
\hline Avidity & Serum & $0.25 \mathrm{~mL}$ & Cool & $\begin{array}{l}\text { For pregnant } \\
\text { woman }\end{array}$ \\
\hline \multirow[t]{4}{*}{ Subinoculation ${ }^{c}$} & Buffy coat & $\begin{array}{l}1 \mathrm{~mL} \text { purple top } \\
\text { (EDTA) tube }\end{array}$ & Cool & Do NOT freeze \\
\hline & Clot & $\begin{array}{l}1 \mathrm{~mL} \text { (from same } \\
\text { red top tube as } \\
\text { whole blood) }\end{array}$ & Cool & Do NOT freeze \\
\hline & Placenta & $200 \mathrm{~g}^{6}$ & Cool & Do NOT freeze \\
\hline & Other tissue & $1 \mathrm{~g}$ (minimum) & Cool & Do NOT freeze \\
\hline \multirow[t]{6}{*}{ PCR } & Buffy coat & $\begin{array}{l}1 \mathrm{~mL} \text { purple top } \\
\text { (EDTA) tube }\end{array}$ & Cool & Do NOT freeze \\
\hline & Amniotic fluid & Unspun $10-20 \mathrm{cc}$ & Cool & Do NOT freeze \\
\hline & Placenta & $\begin{array}{l}\text { Same } 200 \mathrm{~g} \text { as } \\
\text { above }\end{array}$ & Cool & Do NOT freeze \\
\hline & $\mathrm{CSF}$ & $0.5-1 \mathrm{~mL}$ & Cool or frozen ${ }^{\circ}$ & \\
\hline & Other tissue & $25-50 \mathrm{mg}$ & Cool or frozen & \\
\hline & Urine & $\begin{array}{l}\text { Sediment from } \\
\qquad 5 c\end{array}$ & Cool or frozen & \\
\hline
\end{tabular}

a From peripheral blood. Do NOT use umbilical cord blood.

${ }^{\circ} \mathrm{Cool}=$ Use ice packs. Do NOT freeze subinoculation samples or EDTA

tubes.

- Subinoculation $=$ Samples for subinoculation must be shipped promptly by overnight courier and received in laboratory within 72 hours of collection. Amounts differ depending on reference laboratory performing this procedure. - Frozen $=\leq-20^{\circ} \mathrm{C}$. Note: only for PCR; NOT placenta, clot, or buffy coat. Placenta must NOT be frozen.

Commercially available tests that are reliable when performed in accredited hospital laboratories: $\mathrm{Tg}$ IgG; Avidity.

Fig. 2 continued

and prompt fetal treatment via Pyrimethamine, Sulfadiazine, and Leucovorin (PSL) administered to the pregnant woman. Infection may be detected by amniotic fluid PCR of the 20 copy $T$. gondii $\mathrm{B} 1$ gene or the more sensitive 300 copy repeat gene of unknown function [115] at 17 weeks or later in gestation. PSL maternal therapy is administered to the 


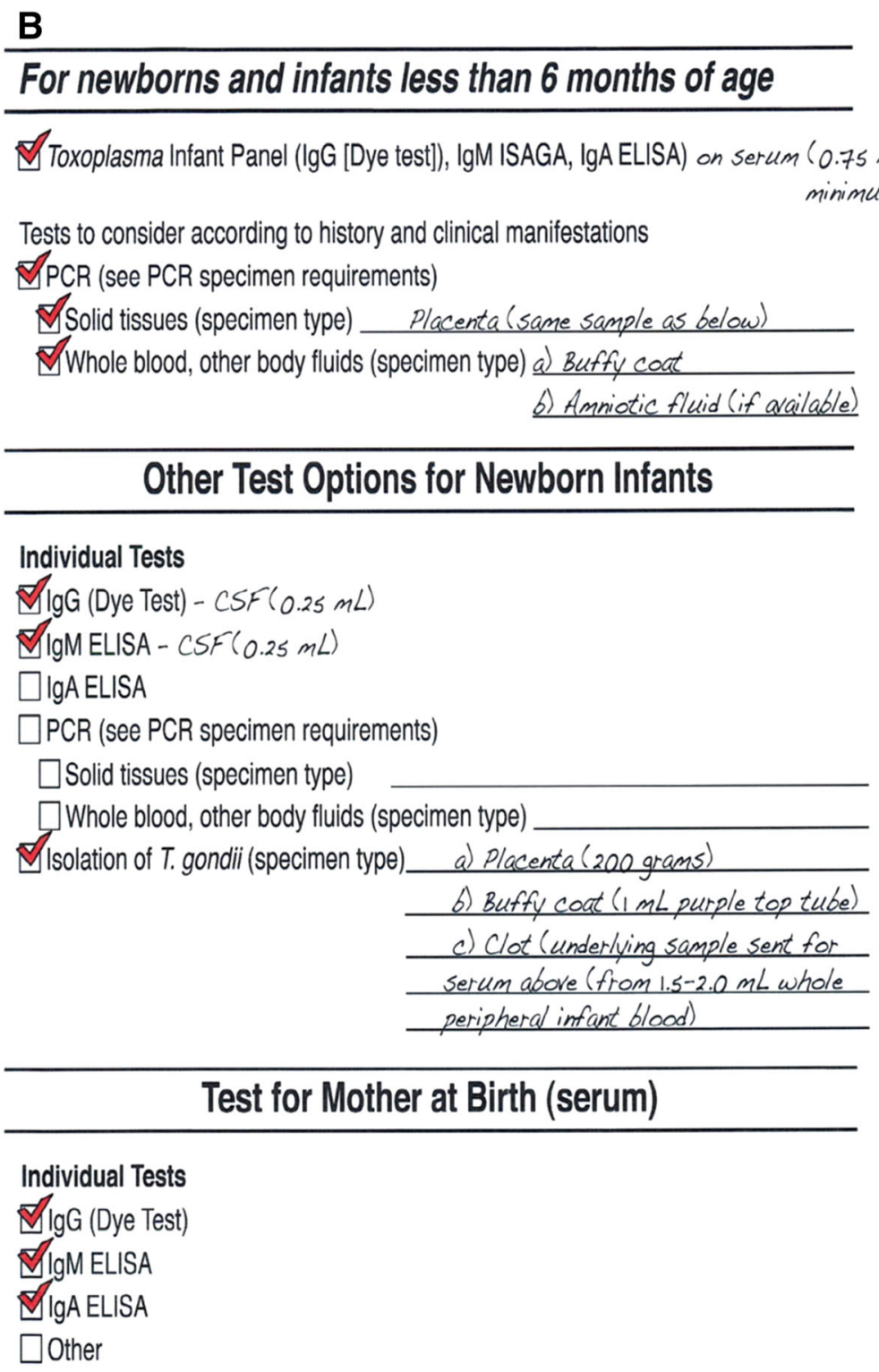

C

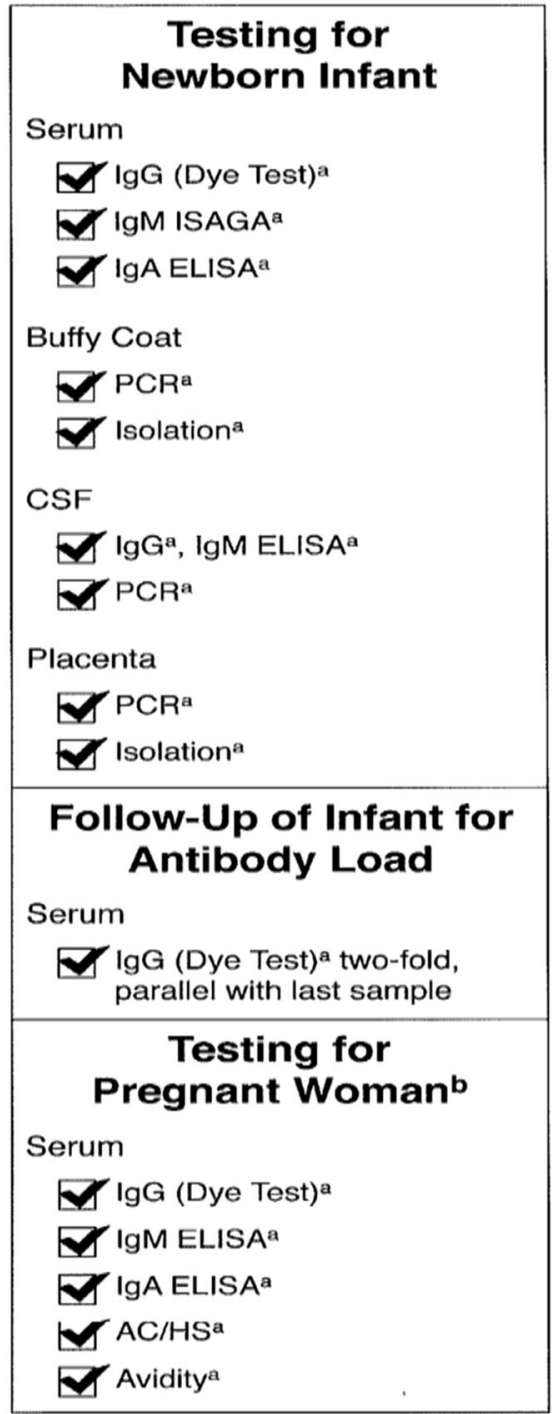

Fig. 2 continued

pregnant women after the 11th week in T. gondii PCRpositive pregnancies; Sulfadiazine is used alone before that time. Findings compatible with toxoplasmosis in the fetus of an acutely infected pregnant woman should also prompt treatment. Pyrimethamine is not used in the first trimester due to possible teratogenic effects. An alternate approach of treating all acutely infected pregnant women with Pyrimethamine, Sulfadiazine, and Leucovorin, again withholding Pyrimethamine in the first trimester, was developed in Austria [118]. This appears to be equally effective in promoting favorable outcomes in the newborn infant and subsequently, later in life, for the congenitally infected person $[81 \bullet, 118]$. Treatment of the fetus is followed by treatment of the infant throughout the first year of life for congenital toxoplasmosis with Pyrimethamine, Sulfadiazine, and Leu-

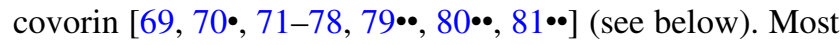
patients whose infection is detected and treated during fetal life are doing well as young adults as demonstrated in longitudinal studies in Lyon, France (Fig. 1). The more rapid the diagnosis (Table 1; Fig. 2) and consequent rapid initiation of treatment (Table 2; Fig. 3), the better the outcomes $(69,70$, 71-78, 79••, 80••, 81••, 207; Figs. 1, 4).

\section{Diagnosis of the Newborn Infant}

This can be accomplished by recognition of clinical findings compatible with the congenital infection in the infant 
D

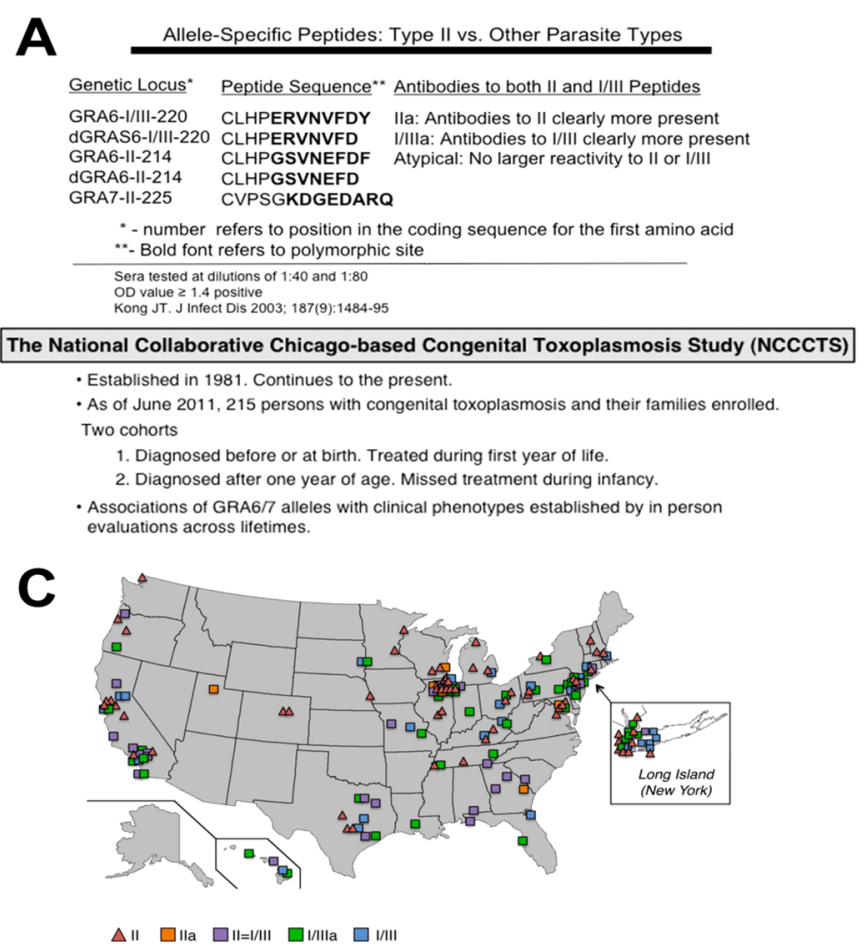

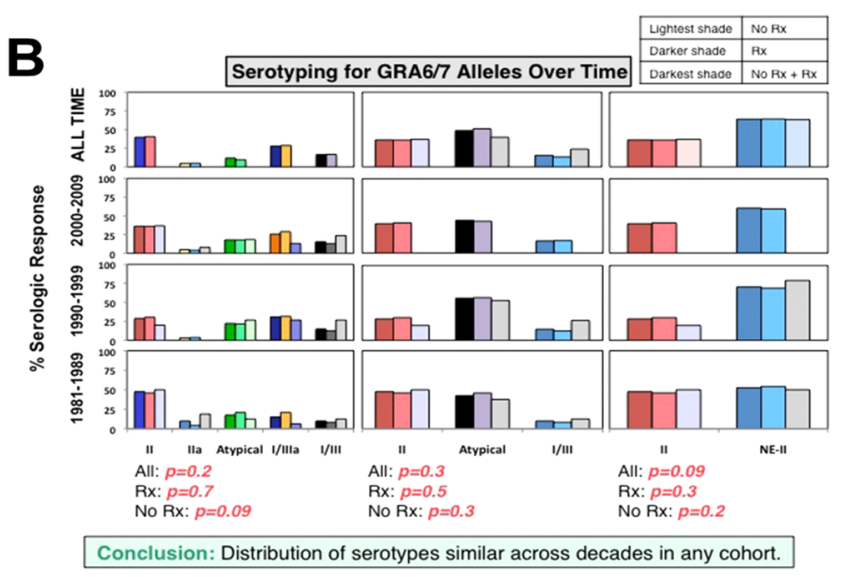

D

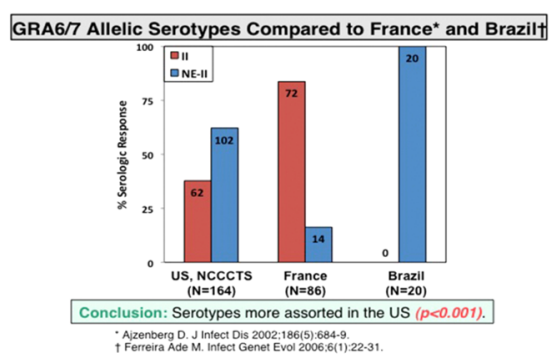

Fig. 2 continued

of an acutely infected mother (Table 1, Fig. 2). Typical clinical findings include prematurity, intrauterine growth retardation, being small for gestational age, "rule out sepsis," blueberry muffin rash, petechiae, hepatitis, splenomegaly, hepatomegaly, anemia, leukopenia, thrombocytopenia, abnormal cerebrospinal fluid cells, protein, or glucose, IgM specific for $T$. gondii or cerebrospinal fluid with $T$. gondii-specific DNA present demonstrated by PCR, intracerebral calcifications, microcephalus, hydrocephalus, chorioretinal scars or choroiditis and vitritis, vitreal veils, uveitis, and cataracts. Diagnosis may be confirmed by isolation of $T$. gondii from placenta or peripheral blood buffy coat [95], demonstration of $T$. gondii by PCR of placenta, or serologic testing with the demonstration of $T$. gondii-specific IgM or IgA. These antibodies are present in only approximately $70 \%$ of infected babies. Images depicting some of these findings, and their improvement with treatment, are shown in Figs. 2, 3, 4. In general, disease manifestations among untreated infants are more severe when infection is acquired earlier in pregnancy and less severe when acquired later in gestation, although parasite and host genetics play a major role in outcomes as well $[77,121 \bullet \bullet, 122,123 \bullet \bullet, 124-128,129 \bullet, 130 \bullet, 131,132$, 133••, 134••, 135•, 136•, 137-140, 141•, 142-147]. There appear to be four primary genetic parasite types in the
USA. Type 2 parasites, similar to those in Europe, also are present in the USA. There is less severe disease and risk of prematurity in those with Type 2 infection, although there is not a complete correlation between parasite type and severity of congenital infection. The inoculum size of ingested parasites, including acquisition of oocysts and contaminated meat in epidemic settings, likely also play a role in outcomes [148] Obstructive hydrocephalus due to obstruction of the Aqueduct of Sylvius results in third ventricular dilatation. This pattern of hydrocephalus may be associated with cerebrospinal fluid protein levels of $>1 \mathrm{~g} / \mathrm{dL}$. Obstruction of the Foramen of Monroe can lead to unilateral or bilateral ventricular dilatation. Hydrocephalus can also occur without anatomic obstruction of CSF circulation. For example, communicating hydrocephalus, which may be due to loss of brain parenchyma, or hydrocephalus associated with poor reabsorption of cerebrospinal fluid, presumably due to a fibrotic process, can occur. This latter pathogenesis is apparently similar to that seen in normal pressure hydrocephalus in adults. All patterns of hydrocephalus can benefit from shunt placement (Hutson, McLeod, McLone, Frim, et al., in preparation 2014); the prognosis is guarded if a shunt is not placed or placement is delayed when necessary. 

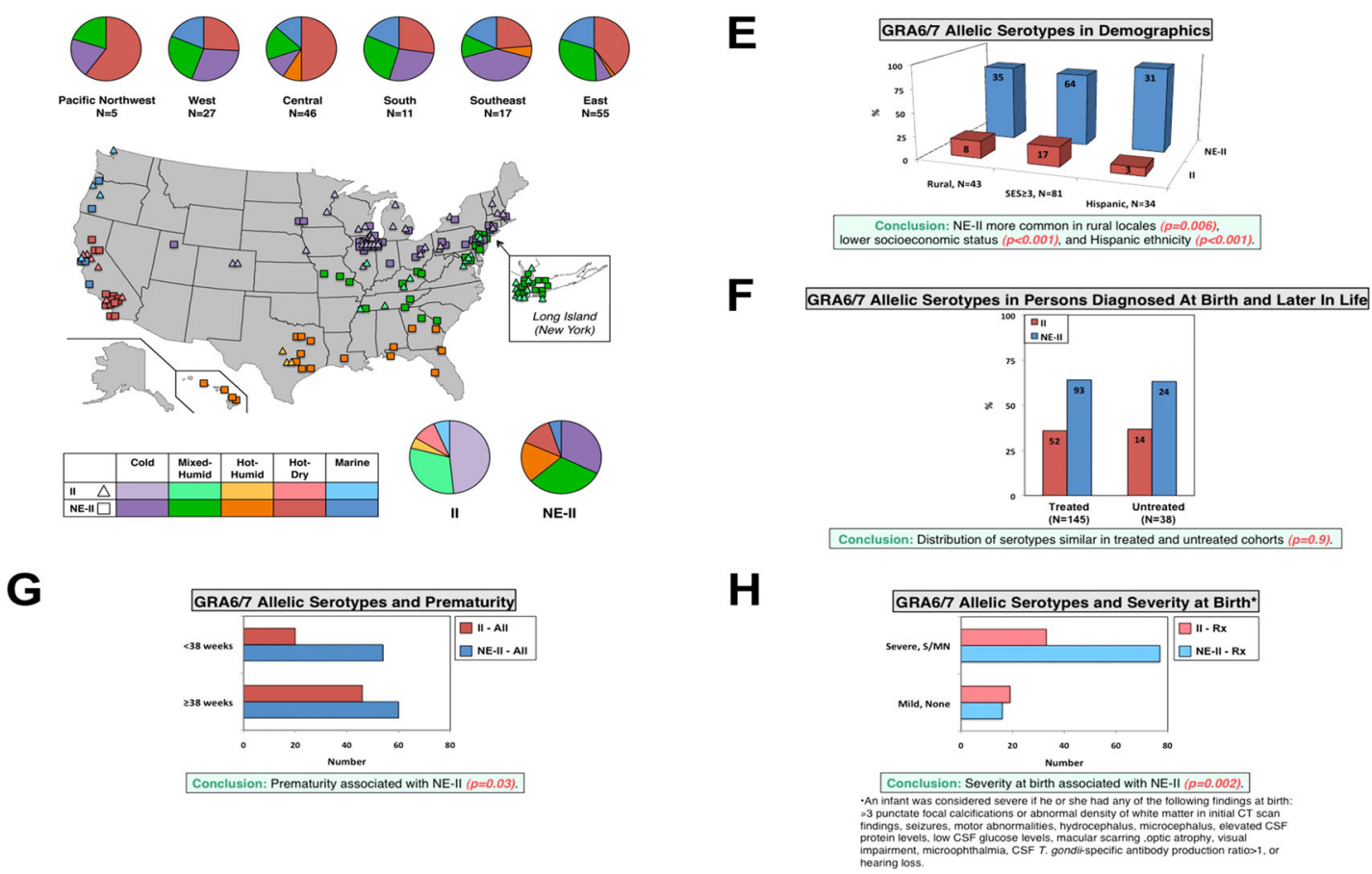

Fig. 2 continued

\section{Treatment of the Infant from Birth to 1 year of Age with Pyrimethamine, Sulfadiazine, and Leucovorin}

Treatment with Pyrimethamine $(1 \mathrm{mg} / \mathrm{kg} / \mathrm{day}$, beginning on the third day following a loading dose of $1 \mathrm{mg} / \mathrm{kg}$ b.i.d. for 2 days), Sulfadiazine $(50 \mathrm{mg} / \mathrm{kg}$ b.i.d.), and Leucovorin (5-10 mg per dose daily or Monday, Wednesday, Friday depending on weight and neutrophil count) from birth to 1 year of age appears to result in much more favorable outcomes than reported for untreated infants earlier $[52,69,70$,

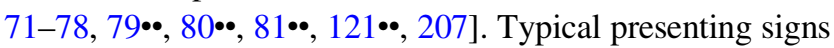
and symptoms, preparation, administration, and monitoring of this treatment and outcomes are summarized in Figs. 2 and 3. Infants are weighed weekly and medications, made fresh each week, are dosed based on increasing weight each week. Signs of active infection and neurologic outcomes appear to be improved relative to those reported in earlier decades without treatment. Signs of active infection appear to resolve early (in weeks) during treatment. Neutrophil counts should be measured via heel prick with only $0.3 \mathrm{~mL}$ of blood collected in a tube for a pediatric complete blood count each Monday and Thursday while taking Pyrimethamine and in the week after this regimen is discontinued. See Table 1 and Fig. 3. Most children have an absolute neutrophil count $~ 900-1,200$ neutrophils $/ \mathrm{mm}^{3}$ during this year of treatment. Leucovorin can be increased to 10-20 mg daily if needed. Pyrimethamine is changed from daily administration to Monday, Wednesday, and Friday dosing after 2 or 6 months. A randomized study did not demonstrate different outcomes with these two dosing schedules for children followed to 15 years of age [74]. Thus, with milder infections, 2 months of daily treatment is often utilized. In cases with more severe initial disease, 6 months of daily treatment is utilized. Leucovorin is continued for a week after Pyrimethamine is discontinued due to the long half-life of Pyrimethamine with its attendant myelosuppressive effects. Care is taken to make certain that the baby's teeth are cleaned after medicine administration because of the sugar-suspending agents leading to the development of dental carries. When neutrophil count is less than 1000 neutrophils $/ \mathrm{mm}^{3}$, a manual differential counting 500 white blood cells is performed to improve accuracy. With neutrophil counts less than 700-1000 neutrophils $/ \mathrm{mm}^{3}$, Leucovorin dosage may be increased to a maximum of $20 \mathrm{mg}$ per day. With less than or equal to 600 neutrophils $/ \mathrm{mm}^{3}$, Pyramethamine and Sulfadiazine are withheld, and Leucovorin continued. These medicines are held until neutrophil count is greater than 1000 neutrophils $/ \mathrm{mm}^{3}$.

\section{Steroid Treatment}

Based on early data from France, Prednisone $(1 \mathrm{mg} / \mathrm{kg} /$ day) is given for a short time with end points being until active vitritis threatening the posterior pole (fovea and optic nerve) of the eye resolves, or when CSF protein declines below $1 \mathrm{~g} / \mathrm{dL}$ if it is initially $>1 \mathrm{~g} / \mathrm{dL}$. Steroids are begun after loading doses of Pyrimethamine with 
Table 1 Adapted from McLeod et al. [207], with permission

Summary of laboratory findings in the diagnosis of toxoplasmosis

- Acute infection (e.g., Lymphadenitis) IgM and IgA serology are positive. Avidity is usually low. If avidity is high, this indicates an infection occurred >12-16 week earlier. A high avidity can be useful to date onset of the infection to longer than 12-16 week. Serial serum specimens at a 3-week interval can demonstrate seroconversion or a rising titer.

- Acute toxoplasmosis in pregnancy The serologic response is similar to that seen for other persons with acute T. gondii infection above; however, the issue for assessing the risk of disease transmission is determining if the infection occurred during or before pregnancy, as $T$. gondii-specific IgM can persist for months or years after the acute infection. Risk for transmission is considered to be present if the infection occurred during pregnancy. The use of IgG avidity (high in most chronic infections, see above), differential agglutination (AC/HS), and the presence of $\operatorname{IgA}$ and/or IgE antibodies (which disappear more quickly than IgM) can help determine the timing of the infection, whether an amniocentesis is indicated to identify congenital toxoplasmosis, or if use of medicines would be helpful

- Chronic infection IgM is negative and IgG is present. Antibody levels do not change with serial specimens. Avidity is high and AC/HS has a chronic pattern

- Reactivation of disease during immune-suppression (e.g., Toxoplasma encephalitis in HIV/AIDS) IgM is negative and IgG may be present. In some cases, there is no detectable serologic response to $T$. gondii. However, if clinical presentation is highly suspicious of infection in the absence of positive serologic results, CSF, blood, and possibly tissue samples should be obtained for diagnosis as indicated. While the sensitivity of PCR has been variable in this setting, if positive, PCR can be useful for diagnosis. In some clinical circumstances, presumptive treatment may be warranted

- Congenital toxoplasmosis For diagnosis in utero for a fetus of an acutely infected pregnant woman who appears to have acquired the infection during gestation, PCR of amniotic fluid and ultrasound imaging of the fetus are used to establish fetal infection. Newborns will be $\mathrm{IgG}$ positive, due to passage of maternal antibody across the placenta. Compatible clinical findings in an infant of an acutely infected mother or the presence of $T$. gondii-specific IgM or IgA in a newborn confirms the diagnosis of congenital infection. Serial serology with a stable or rising IgG titer can also confirm the diagnosis of congenital infection. An example of fall in $T$. gondii-specific antibody load is as follows:
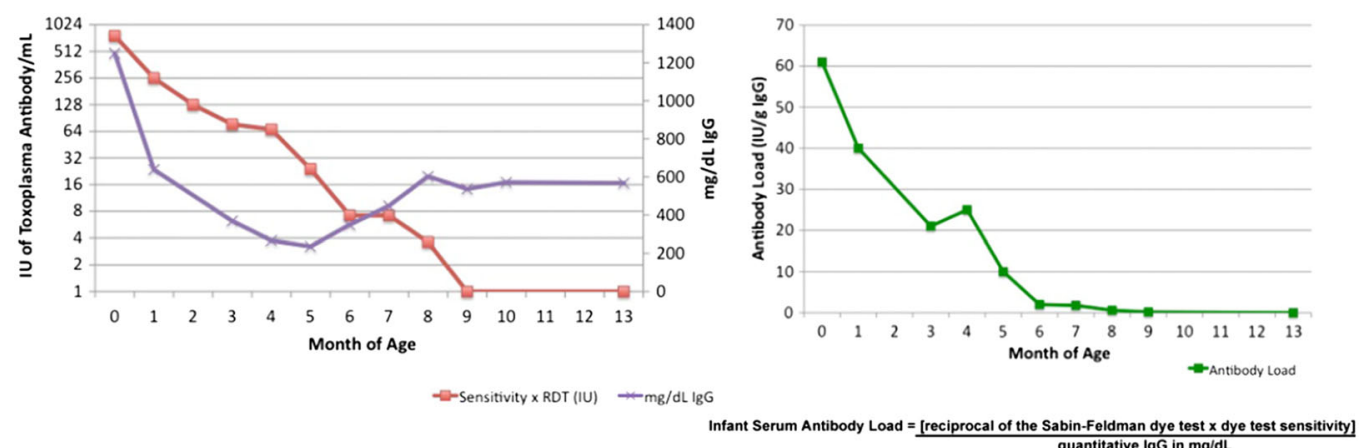

Sulfadiazine have been administered. There have been no randomized controlled studies to demonstrate whether such treatment with Prednisone improves outcomes.

\section{Approach to Cerebral Ventricular Enlargement}

Hydrocephalus due to congenital toxoplasmosis is treated with ventriculoperitoneal shunting. It is not clear from initial neuroimaging studies which children will benefit most from aggressive CSF drainage. This question is further confounded by the observation that despite progressive ventricular dilatation and cortical compression, measured CSF pressures may remain low (Hutson, McLeod, McLone, Frim, et al. in preparation, 96). Thus, it is imperative to proceed as though all children with hydrocephalus would benefit from CSF shunting as early drainage can promote cortical reconstitution and remarkably good functional outcomes. One recent advance in neuroimaging for following hydrocephalus and/or shunt function is a two sequence, 45-s magnetic resonance imaging (MRI) study of the brain, which does not require sedation or contrast administration. This can be used to follow the progress of ventricular dilatation or the correction of hydrocephalus in a manner that is easy and comfortable for both parent and child. There are two sequences, collectively referred to as "brain shunt hydrocephalus screen" in some US hospitals. These two sequences are T2 axial and coronal single shots with images at 3-mm intervals.

Delays in shunt placement have been associated with less favorable outcomes [96]. Endoscopic third ventriculocisternostomy (ETV) frequently fails as a treatment for aqueductal obstruction causing hydrocephalus in this 
Table 2 Guidelines for treatment of toxoplasmosis

Clinical setting and manifestation

- Acute, asymptomatic infection

- Acute infection with self-limited adenopathy, fever, or malaise in immune-competent persons

- Latent, asymptomatic infection detected by positive serologic test

- Severely symptomatic disease in immune-competent adults

- Laboratory infection with $T$. gondii tachyzoites

-Active disease in immune-compromised persons

- In pregnant women infected during gestation:

- First 18 weeks' gestation, or until term, if fetus found not to be infected by amniocentesis at 18 weeks' gestation and to have no clinical findings

- If fetal infection confirmed or if infection acquired after 24 weeks' gestation

- Congenital T. gondii infection in infant

- Active chorioretinitis in older children and adults

- Active choroidal neovascular membrane due to T. gondii infection ${ }^{f}$
Treatment

The current standard of care is no treatment

- Pyrimethamine ${ }^{\mathrm{b}}$, Sulfadiazine ${ }^{\mathrm{d}}$, and Leucovorin (folinic acid) ${ }^{\mathrm{b}}$

- Spiramycin ${ }^{\mathrm{a}}$

- Pyrimethamine $^{\mathrm{b}} *$, Sulfadiazine ${ }^{\mathrm{d}}$, and Leucovorin (folinic acid $\}^{\mathrm{b}}$

* Do NOT use Pyrimethamine in the first 14 week of gestation

- Pyrimethamine ${ }^{\mathrm{b}, \mathrm{c}}$, Sulfadiazine ${ }^{\mathrm{d}}$, and Leucovorin (folinic acid) ${ }^{\mathrm{b}}$

- Occasionally corticosteroids (prednisone) ${ }^{\mathrm{e}}$ have been used when CSF protein is $\geq 1 \mathrm{~g} / \mathrm{dL}$ or when active chorioretinitis threatens vision

- Pyrimethamine $^{\mathrm{b}}$, Sulfadiazine ${ }^{\mathrm{d}}$, and Leucovorin (folinic acid) ${ }^{\mathrm{b}}$

- Corticosteriods (prednisone) ${ }^{\mathrm{e}}$ if macula or posterior pole is involved or vitritis threatens vision

- Pyrimethamine ${ }^{\mathrm{b}}$, Sulfadiazine ${ }^{\mathrm{d}}$, and Leucovorin (folinic acid) ${ }^{\mathrm{b}}$

- Lucentis (antibody to VEGF) used as in algorithm' below

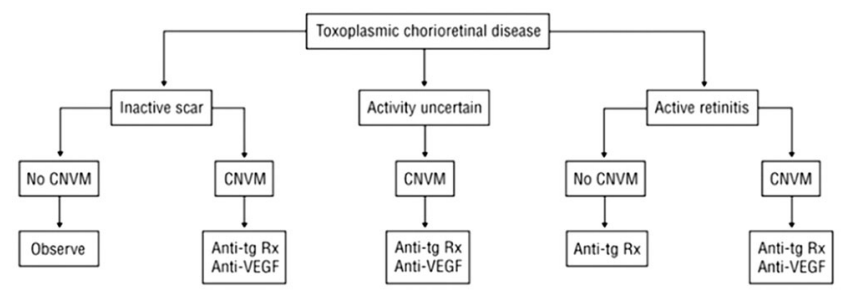

Table and caption adapted from Remington et al. [98••] with permission

${ }^{a}$ In the USA, available only on request from the U.S. Food and Drug Administration (telephone number 301-443-5680), and then with this approval by the physician's request to Aventis (908-231-3365)

b Adjusted for granulocytopenia; complete blood counts, including platelets, should be monitored each Monday and Thursday. A standard adult dose for a $50-\mathrm{kg}$ person is $50 \mathrm{mg}$ bid for the first 2 days then $50 \mathrm{mg}$ per day Pyrimethamine beginning on the third day. A standard dose of Leucovorin for a $50-\mathrm{kg}$ person is $10 \mathrm{mg}$ daily

${ }^{c}$ Both regimens, a higher and a lower dose, appear to be feasible and relatively safe. The duration of therapy is unknown for infants and children, especially those with AIDS

d A standard dose of Sulfadiazine for a 50- to 75-kg person is $1.5-2 \mathrm{~g}$ per day bid with 8 glasses of water or non-acidic beverages each day to limit development of nephrolithiasis. Alternative medicines for patients with atopy or severe intolerance of sulfonamides have included Pyrimethamine and Leucovorin with clindamycin or azithromycin or atovaquone, with standard dosages as recommended according to weight. In the unusual circumstance that medicines cannot be administered orally or by intraintestinal tube feeding, trimethoprim, sulfamethoxazole, and clindamycin have been administered intravenously

${ }^{\mathrm{e}}$ Corticosteroids should be used only in conjunction with Pyrimethamine, Sulfadiazine, and Leucovorin treatment and should be continued until signs of inflammation (high CSF protein, $\geq 1 \mathrm{~g} / \mathrm{dL}$ ) or active chorioretinitis that threatens vision have subsided, ususally $\sim 10-14$ days; dosage can then be tapered and the steroids discontinued

${ }^{\mathrm{f}}$ Image figure from: Benevento et al. [173], with permission

disease [96] and should not be used [96]. A possible cause of this failure of ETV is entry of inflammatory CSF into the subarachnoid space, resulting in adhesions and inadequate CSF absorption. It is not uncommon for children to have cortical expansion and restoration of normal ventricular volume and neurologic function (Fig. 4). High CSF protein and diabetes insipidus have been linked to less favorable outcomes, but this is not absolute. 
Fig. 3 Treatment of congenital toxoplasmosis. a Instructions for the preparation, administration, and storage of Pyrimethamine, Sulfadiazine, and Leucovorin. Adapted with permission from McLeod et al. [206, 207]. b Administration of these medicines in management of congenital $\mathrm{T}$. gondii infection in the first year of life. Adapted with permission from McLeod et al. [206, 207].

c Pyrimethamine:

pharmacokinetics and consequences of its use pharmacokinetics of Pyrimethamine, as well as potential toxic effects of the medicine. Hypersensitivity secondary to Sulfadiazine. Adapted with permission from McLeod et al. [206, 207]

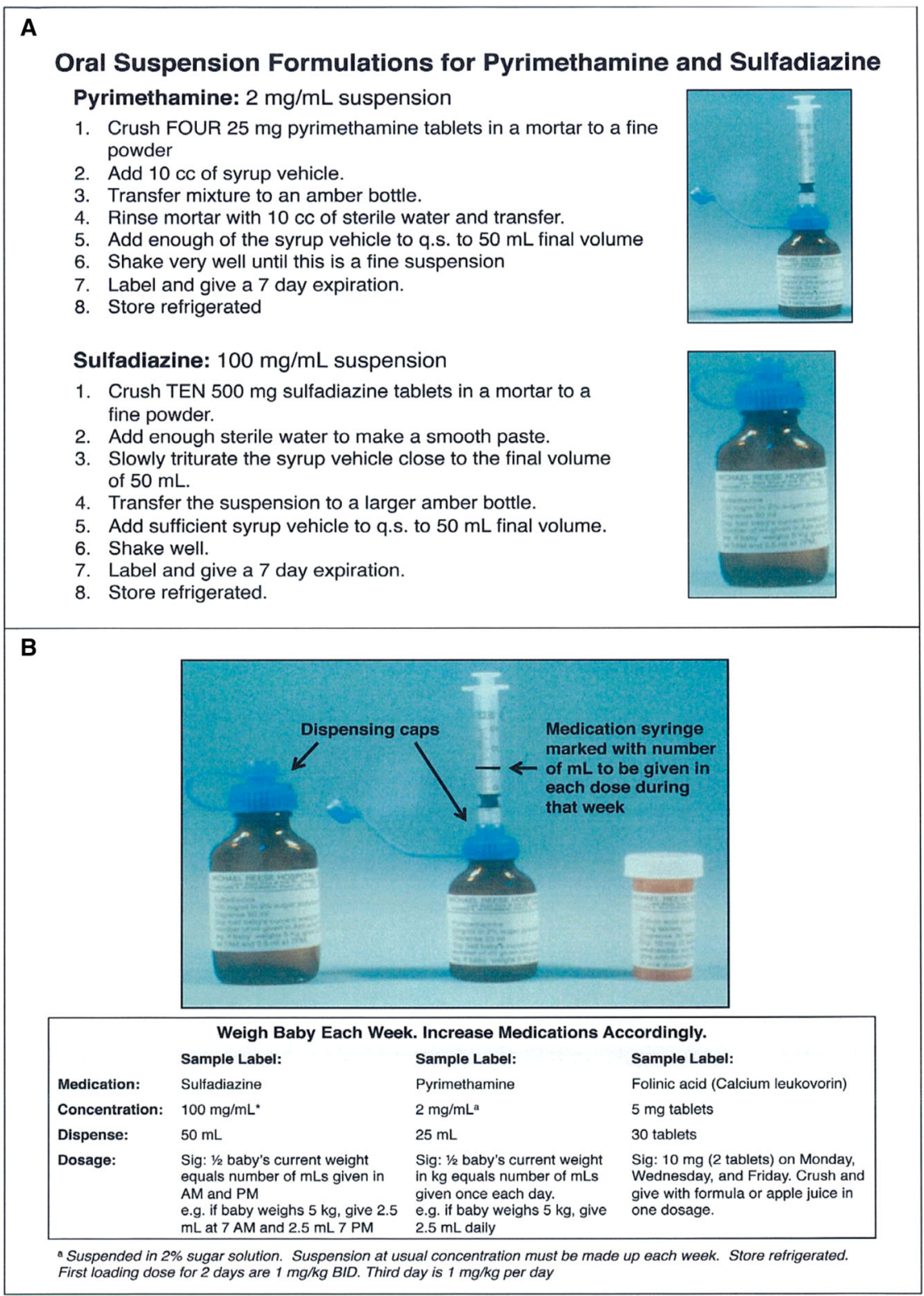

\section{Seizures and other Neurologic Findings Early in Infancy and Later}

Seizures due to $T$. gondii have been treated effectively with Levetiracetam $\left(\right.$ Keppra $\left.^{\circledR}\right)$. In contrast to Phenobarbital, this anti-epileptic does not induce hepatic enzymes that degrade Pyrimethamine. It does not displace Sulfadiazine binding from albumin, as Phenytoin (Dilantin ${ }^{\circledR}$ ) does, nor does it trigger the bone marrow toxicity associated with Carbamazepine $\left(\right.$ Tegretol $^{\circledR}$ ). It has less sedative hypnotic type effects than certain other anti-epileptic medicines. In some cases, intractable myoclonic seizures associated with recurrent central nervous system disease responded to ketogenic diet therapy (McLeod, Swisher, Hood, Heydemann, et al. in preparation). In some cases, treatment of the acute encephalitic findings caused by active $T$. gondii in the perinatal period, with Pyrimethamine and Sulfadiazine, has made it possible to discontinue anti-epileptic medicine without recurrence of seizures upon their discontinuation. It is not common to develop progressive and/or recrudescent central nervous system disease in treated children, but it can occur and may present as new seizures (McLeod et al., in preparation, 2014). Serum, CSF, neuroimaging, and biomarkers indicate that this is secondary to active central nervous system disease and parasite proliferation (McLeod et al. in preparation 2014). 
C

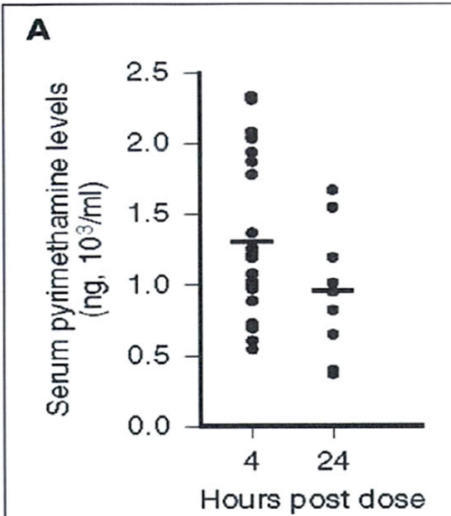

B

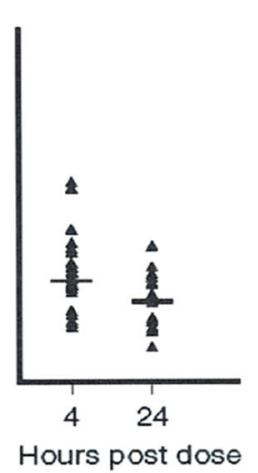

C

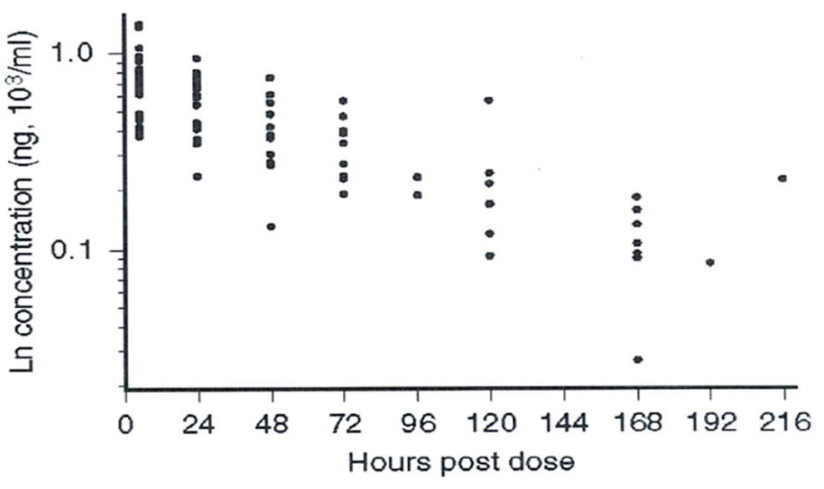

D Pyrimethamine

Pharmacokinetics and Toxicity

- Pyrimethamine half life $=64 \pm 12$ hours

- Serum levels with $1 \mathrm{mg} / \mathrm{kg} / \mathrm{d}$ dose $=1.3 \pm 0.5 / \mathrm{ugm} / \mathrm{ml} 4 \mathrm{hrs}$ after dose

- CSF levels are approximately $10 \%-25 \%$ concomitant serum levels

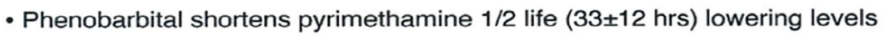

- Serum and CSF levels in potentially therapeutic range (in vitro studies)

- Toxicity: reversible neutropenia, discoloration teeth (sugar suspensions)

- Similar incidence of reversible neutropenia for high and low dose

E Episodes of Reversible Neutropenia Requiring Temporary Withholding of

No. Episodes Medication
Withheld

(Mean \pm S.D. [RANGE])

Treatment A

Treatment $\mathrm{C}$
$2 \pm 1$ [1-4]

$3 \pm 3[1-11]$
No of Patients Who Stopped Medication/ No. in Cohort Who Have Completed 1 Year of Therapy (\%)

Feasibility Randomized

$6 / 14(43)$

$6 / 11(55)$
$13 / 36$ (36)

$10 / 28(36)$
Toxicity and Complications

- Reversible neutropenia requiring temporary withholding of medications did not differ for treatment groups

Eleven deaths, not related to treatment

$\mathbf{F}$
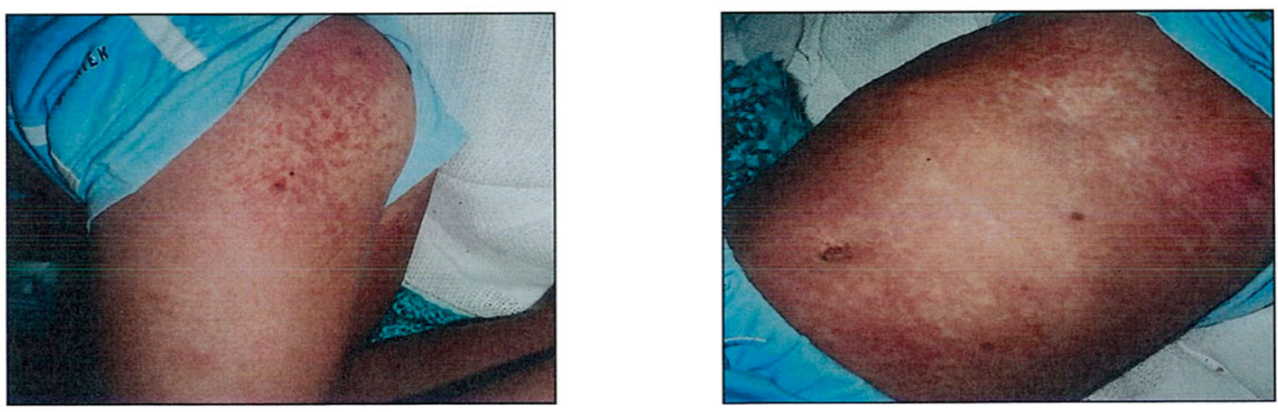

No. Who Discontinued Medications

Due To Neutropenia $\geq 4$ Times

\section{AlI}

$21 / 57(37)$

20/59 ()
2

7

Fig. 3 continued

Earlier studies [4, 64, 65] suggested recurrent and/or progressive disease occurred in untreated children. To date, relapsing central nervous system infection is uncommon in treated children in the National Collaborative ChicagoBased Congenital Toxoplasmosis Study (NCCCTS), which encompassed most of the clinical experience based on direct observation in a single center longitudinal study in North America from 1981 to the present. The incidence and extent of unrecognized CNS sequelae [148, 149••, $150 \bullet \bullet, 151,152 \bullet \bullet, 153-157,158 \bullet, 159-161]$ in postnatally or congenitally infected children remain to be determined.

\section{Recrudescent Eye Disease and Management of Active Retinitis After the First Year of Life}

Retinal disease due to $T$. gondii becomes quiescent with treatment in the first year of life [162-164, 165••, 166••, 167, 168], with fewer recurrences in promptly treated children than for those referred after the first year of life (Fig. 4). Recurrence occurs most frequently at the age of school entry, in puberty and adolescence (Fig. 4), and in the presence of substantial stress (e.g., bereavement, surgery, or trauma). Pyrimethamine, Sulfadiazine, and Leucovorin are used in retreatment 
(Table 2). Active infection in all parts of the retina require therapy; prompt therapy is associated with more rapid lesion resolution. Treatment is continued for several weeks after the borders of the lesions become sharply demarcated and the edges pigmented (Fig. 4). This often occurs within a few weeks after initiating treatment. If there is hypersensitivity to sulfonamides, Azithromycin is offered instead of Sulfadiazine. Azithromycin suppressive therapy has been utilized successfully in patients with recurrent chorioretinitis following resolution of active disease, particularly when recurrence of lesions is vision threatening. Although TMP-SMX successfully suppressed recurrences in a series in Sao Paulo, Brazil [168], it had an unacceptably high incidence of hypersensitivity. TMP/SMX suppression may lead to sulfonamide hypersensitivity and appears to be less efficacious than Pyrimethamine plus Sulfadiazine treatment, likely due to suboptimal TMP/SMX dose ratios and lesser efficacy of TMP than Pyrimethamine and SMX than Sulfadiazine. The optimal duration of prophylaxis to prevent the loss of vision or frequently recurring retinal disease has not been determined.

\section{Choroidal Neovascular Membranes}

Choroidal neovascular membranes (CNVM) [169, 170, 171•] occur rarely as a complication of chorioretinal disease due to $T$. gondii infection. Diagnosis is determined by clinical examination with the findings of subretinal blood or fluid, leaky vasculature visualized by fluorescein angiography and ocular coherence tomography (OCT). Infection with $T$. gondii drives increased expression of hypoxia-inducible factor $1-\alpha$ (HIF1- $\alpha$ ), which leads to increased levels of vascular endothelial growth factor (VEGF) transcription. VEGF promotes the growth of new blood vessels. Infiltration of vasculature arising from the choroid disrupts Bruch's membrane, causing retinal scars. Fluid accumulates in the subretinal space. Hemorrhage can result from new, leaky blood vessels with resultant sudden loss of vision. This pathologic process can be abrogated by antibodies against VEGF. Ranibizumab (Lucentis ${ }^{\circledR}$ ), in conjunction with standard anti-parasitic therapies, has been used. Bevacizumab (Avastin $\left.{ }^{\circledR}\right)$ treated persons also had improved outcomes with CNVM due to toxoplasmosis. These $\alpha$-VEGF medicines are injected intravitreally. Dosages can be found in Table 2. Infants have received $\alpha$-VEGF safely for retinopathy of prematurity, but we are unaware of their use for CNVM due to $T$. gondii [170]. The recommended form of management for this complication is $\alpha$-VEGF, in combination with anti-parasitic medications. This regimen has been effective in persons with CNVM due to $T$. gondii. Photodynamic therapy has also been reported to have efficacy $[169,170,171 \bullet]$.
Fig. 4 Manifestations of congenital toxoplasmosis and outcomes of treatment. a Neurologic manifestations of congenital toxoplasmosis and response to treatment. Brain CT images depicting the impact of proper shunt placement and treatment of congenital toxoplasmosis on the course of hydrocephalus secondary to $T$. gondii infection. Adapted with permission from McLeod et al. [207]. b Congenital toxoplasmosis, its impact on the retina, and the effect of treatment on eye lesions. Effect of treatment on the recurrence of eye lesions secondary to $T$. gondii infection, with increased frequency of occurrence at entrance into school and at adolescence. c Response of active eye lesions to treatment. Treatment of eye lesions leads to resolution of overlying vitritis, hazy margins and sharp demarcation and hyperpigmented lesions. d Choroidal neovascular lesions and their response to anti-T.gondii treatment and antibody to VEGF. The first image is a patient with choroidal neovascular membrane and the resultant resolution with treatment. Note the presence of blood and subretinal fluid, which decreases following treatment with appropriate therapy. Adapted with permission from Benevento, McLeod et al. [206, 207]. Additional choroidal neovascular membranes and their response to treatment in additional patients. The impact of prompt, appropriate treatment of choroidal neovascular membranes in a series of patients. Evidence of bleeding decreases, as does the presence of subretinal fluid in these patients. Adapted with permission from Benevento, McLeod et al. [206]. e Literature outcomes in congenital toxoplasmosis and outcomes in the NCCCTS cohort. A comparison of frequency of outcomes as reported by literature and within the National Collaborative Chicago-based Congenital Toxoplasmosis Study cohort. Note the dramatic decreases in the frequency of outcomes in this particular cohort relative to literature sources. This is true for many outcomes, including IQ, motor function, retinal lesions, and central nervous system manifestations. Adapted with permission from McLeod et al. [206, 207]. f The treatment of congenital toxoplasmosis, in utero, and outcomes due to this early treatment. The impact of treatment, in utero, on the frequency of disease manifestation in congenital $T$. gondii infection. Note the increased frequency of most disease manifestations without the initiation of treatment, in utero. Adapted with permission from and McLeod et al. [207]. g Parasite serotype and its relationship to treatment efficacy. Tabular representation of the impact of parasite type on outcomes in treated patients. Postnatal treatment was effective (i.e., improved outcomes) in both type II and type NE-II parasites, indicating that both respond to treatment. Adapted with permission from and McLeod et al. [207]. h Outcomes in NCCCTS cohort compared to the literature. Data indicating improved outcomes in treated patients over preexisting literature data on pre-established endpoints, including neurologic outcomes, reductions in IQ, worsened vision, new retinal lesions, and hearing loss. Adapted with permission from McLeod et al. [206, 207]. (I) Dosage of Pyrimethamine and its Impact on Treatment Outcomes. Kaplan-Meier plots indicating no significant differences in outcomes between two treatment arms receiving higher doses of Pyrimethamine versus lower doses. In practice, infants with less severe manifestations often receive the lower dose of Pyrimethamine, though with severe disease often are still treated with higher doses. Adapted with permission from McLeod et al. [206, 207]

\section{Implications of Congenital Infection for Family Members and Those who Share Risk Factors for Acquisition of Infection}

Acquisition of $T$. gondii infection by multiple family members due to common exposures is not infrequent. Thus, 
A
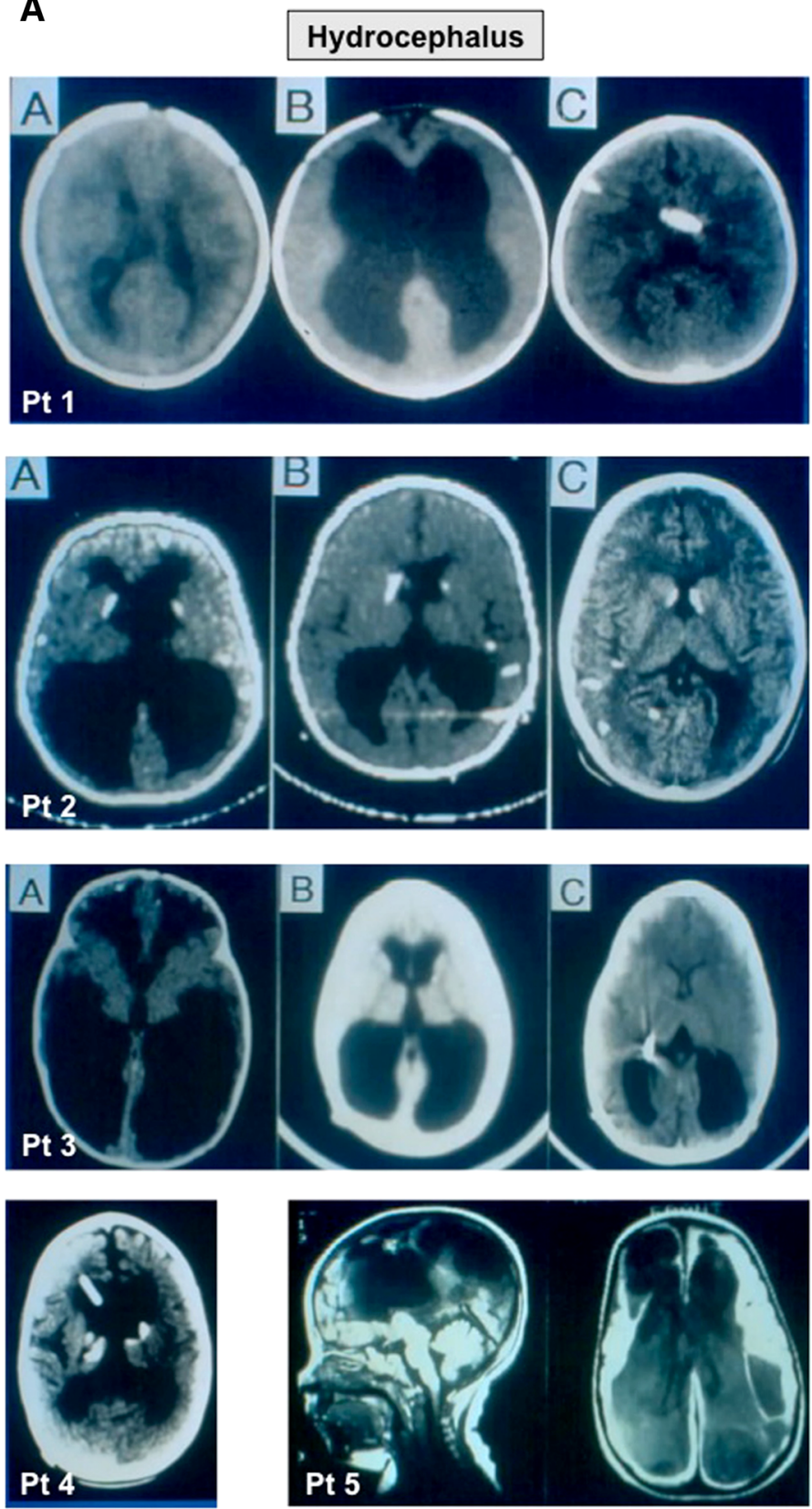

Conclusions: Hydrocephalus often improves in association with shunting and medical treatment.
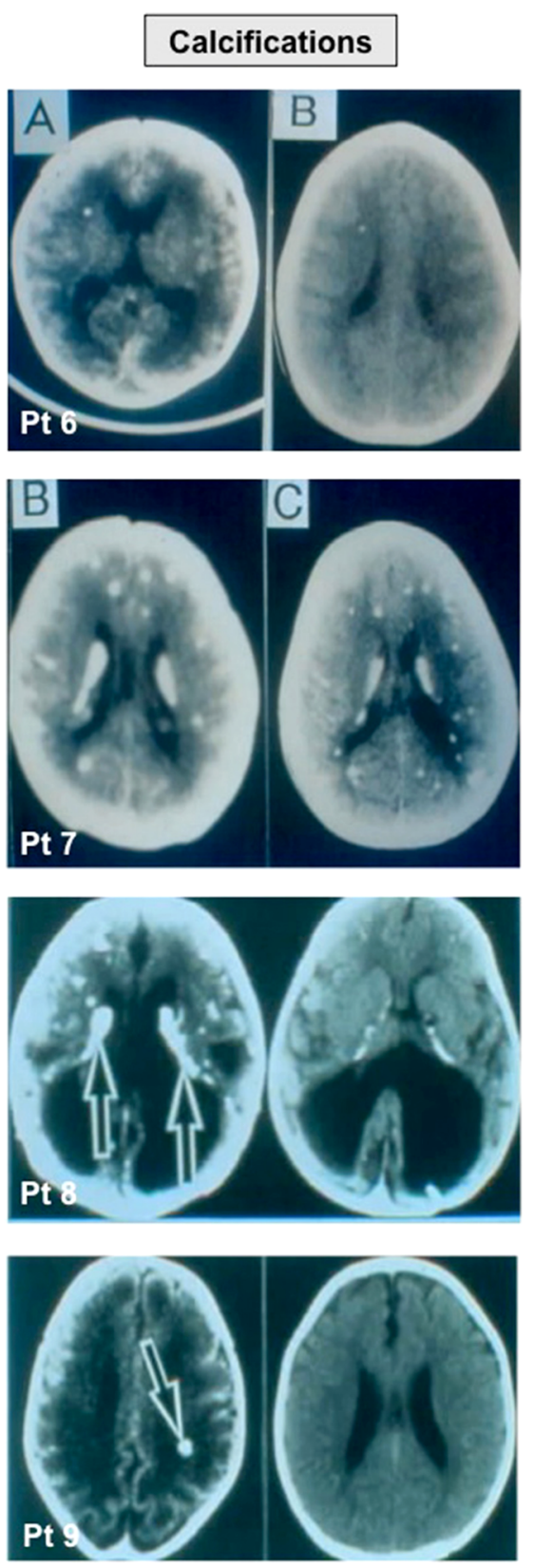

Conclusions: Calcifications often diminish in association with treatment. it is reasonable to determine whether other family members were also acutely infected at the time a pregnant woman has acquired infection or a congenitally infected baby is born. Because retinal disease may occur in up to $10 \%$ of mothers of infected babies and may occur in family members who could benefit from treatment, it may be prudent to also test other family members of infected babies $[172,173]$.

\section{Prognosis}

Many children born with congenital toxoplasmosis who are treated in utero and throughout the first year of life have normal cognitive development and function well, being able to continue on to university and having families of their own. There is more retinal disease among children born in the USA who missed being treated in utero and 
B
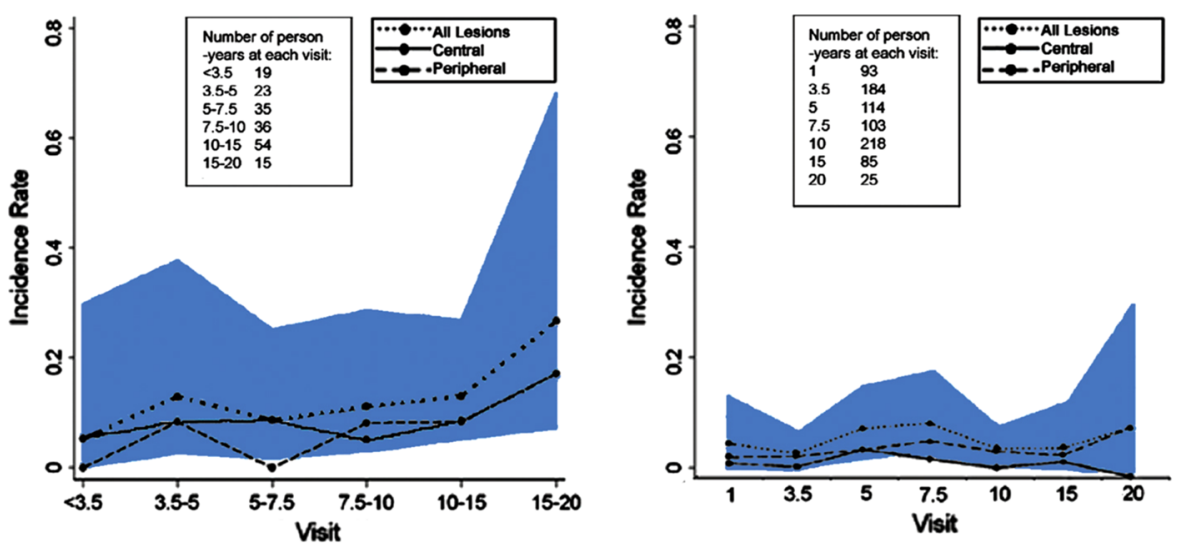

C
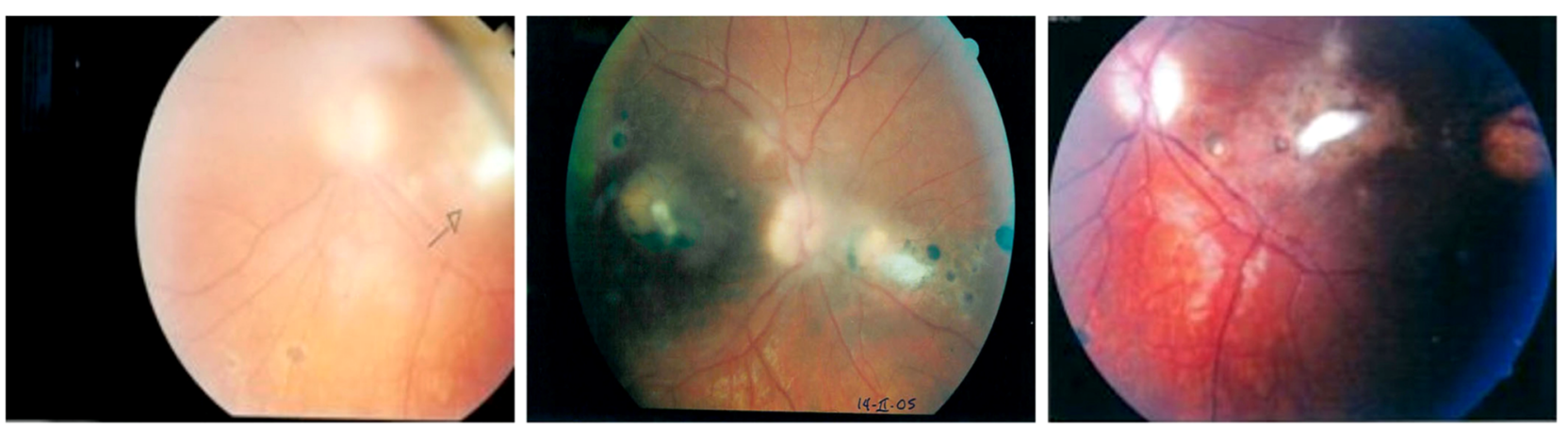

D
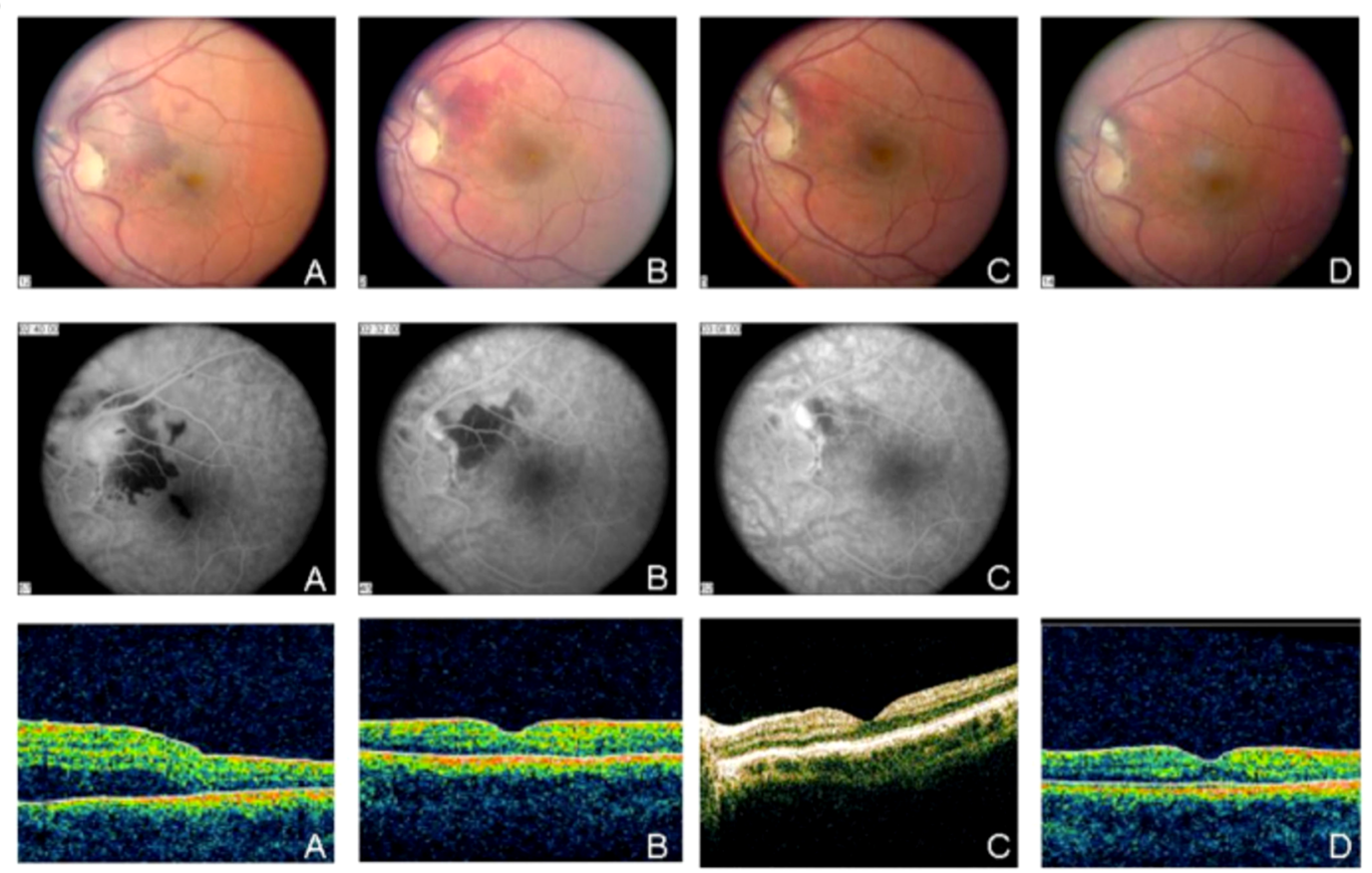

Fig. 4 continued

appears to occur more often in those who were not diagnosed and treated in the first year of life. There is a gradation in outcomes from severe impairment to completely functional children and young adults, both with and without treatment in the first year of life. It appears that outcomes with treatment for those who are born with moderate 

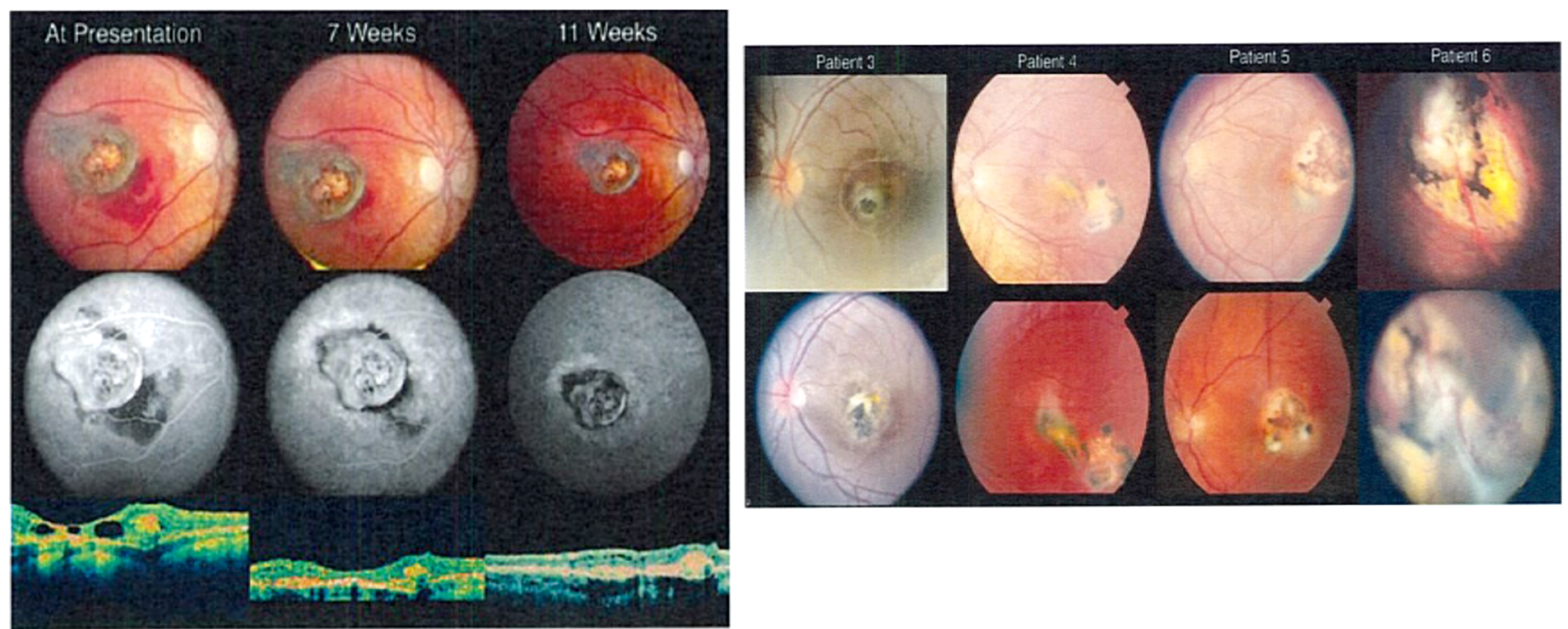

\begin{tabular}{|c|c|c|c|c|c|c|c|c|c|}
\hline Patent & $\begin{array}{l}\text { Age at bine of } \\
\text { Meovascular } \\
\text { Lesion Noted }\end{array}$ & $\begin{array}{l}\text { Lesion } \\
\text { Type }\end{array}$ & $\begin{array}{l}\text { Probable } \\
\text { Durafion of } \\
\text { Lesion }\end{array}$ & $\begin{array}{c}\text { Ambi- } \\
\text { parasific } \\
\text { Treatment: }\end{array}$ & $\begin{array}{l}\text { Treaiment of } \\
\text { Neovascular } \\
\text { Lesion } \\
\text { (\# of Iniections) }\end{array}$ & $\begin{array}{l}\text { Prelesion } \\
\text { Visual } \\
\text { Acuity }\end{array}$ & $\begin{array}{c}\text { Visual Acuity at } \\
\text { Trme of } \\
\text { Treatment }\end{array}$ & $\begin{array}{l}\text { Post: } \\
\text { Treaimert } \\
\text { Visual } \\
\text { Acuiny }\end{array}$ & $\begin{array}{l}\text { Tme to } \\
\text { Resolujion' } \\
\text { Duration of } \\
\text { Foliow Up }\end{array}$ \\
\hline 1 & 25 years & CNVM & 1 meek & Yes & $\begin{array}{c}\text { Ranbizuma b } \\
\text { (2) }\end{array}$ & 2000 & 2060 & 20120 & $\begin{array}{l}2 \text { months' } \\
1 \text { year } 3 \text { nonths }\end{array}$ \\
\hline 2 & 7 years & CrVy & >1 manth & Yes & $\begin{array}{c}\text { Ranbizuna b } \\
\mid(3)\end{array}$ & 20140 & $\mathrm{HM}$ & $2 a r c 0$ & $\begin{array}{l}11 \text { weaks' } \\
1 \text { year }\end{array}$ \\
\hline 3 & 11 years & CNVN & $<1$ year & No & POT & 20140 & 2060 & 2030 & $\begin{array}{c}\text { NAN } \\
15 \text { years }\end{array}$ \\
\hline 4 & 4 years & CNVN & $<1$ year & Yes & None & 20100 & 20150 & 20150 & $\begin{array}{l}\text { NA } \\
6 \text { years }\end{array}$ \\
\hline 5 & 6 yeass & CNVM & $>2$ years & Yes & None & 20130 & 2030 & 20125 & $\begin{array}{c}\text { NAI } \\
13 \text { years }\end{array}$ \\
\hline 6 & 15 years & Angiona & $>6$ morths & Kes & Ranitciuma b & 20130 & $20 / 40$ & $\begin{array}{c}\text { Not } \\
\text { analable }\end{array}$ & In progress \\
\hline
\end{tabular}

Fig. 4 continued

or severe involvement at birth are markedly better than that reported in the older literature for those who were not treated or treated for only 1 month [43, 44, 62, 64, 65, 69, $81 \bullet$ ]. Approximately $70 \%$ of children who had generalized systemic or neurologic manifestations and thus would have been expected to have severe disability have done well. Interestingly, for treated children, intracerebral calcifications may resolve partially or completely during the first year of life [90]. However, there may also be significant impairment. Severe involvement may impact quality of life when treatment is started too late to effect a markedly improved outcome [174].

\section{The Future}

At the present time, there is a substantial need for less toxic, improved medicines for tachyzoites and medicines effective against encysted bradyzoites [175-180, 181••, 182-184, $185 \bullet \bullet, 186 \bullet, 187-189]$, as well as an effective vaccine [190•,
$191 \bullet, 192 \bullet, 193 \bullet, 194,195,205]$. There are robust efforts to develop such agents, with recent successes in developing compounds that eliminate bradyzoites and reduce toxicity of treatment of the active infection. These advances are likely to lead to improved approaches to treatments and outcomes for this infection in the near future. Prenatal screening [61, 62, $95,107]$ is another significant advance that likely will occur in the USA during the next decade and result in decreased congenital toxoplasmosis and reduce costs for care [120••, 202•]. Additional insights into pathogenesis are also arising from new genetic studies and associations of ocular disease with unusual parasite types [200•, 201•, 202•, 203•]. Live vaccines can now prevent infections in animal models [203•] and translation of the protective mechanisms to non-live reagents and to clinical use through immuno-sense [194], approaches may offer substantial advances. Whether there is clear cause and effect for congenital toxoplasmosis leading to other neurobehavioral diseases remains to be determined $[196,197,198 \bullet, 199 \bullet, 201 \bullet]$; although it is not evident in the US cohort of families followed from 1981 to the present. 
Fig. 4 continued

E

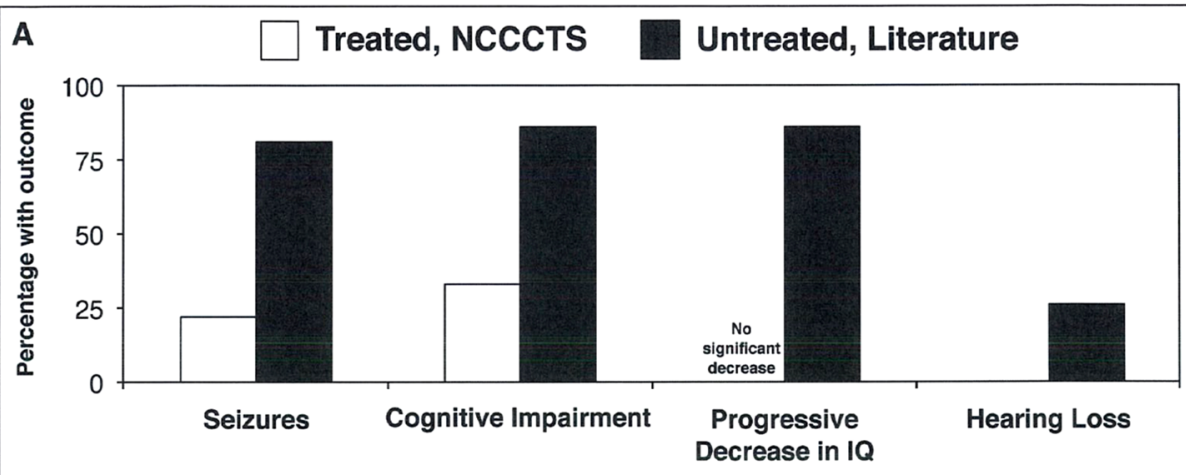

\begin{tabular}{|c|c|c|c|}
\hline Rx - Severe & $\begin{array}{l}\text { No Rx, Literature } \\
\text { - Severe }\end{array}$ & $\begin{array}{l}\text { Rx }- \text { Mild/ } \\
\text { Moderate }\end{array}$ & $\begin{array}{l}\text { No Rx, Literature - } \\
\text { Mild/Moderate }\end{array}$ \\
\hline
\end{tabular}

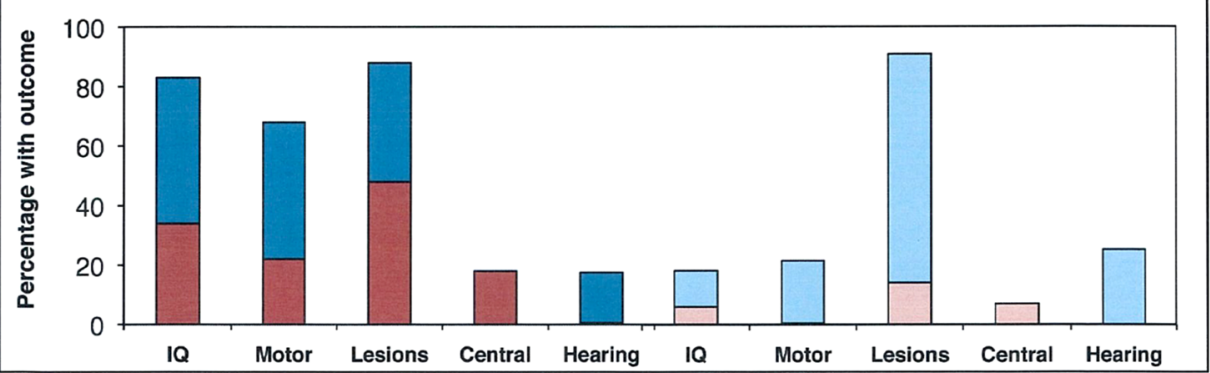

$\mathbf{F}$

\section{Endpoint Outcomes Compared to Literature Data}

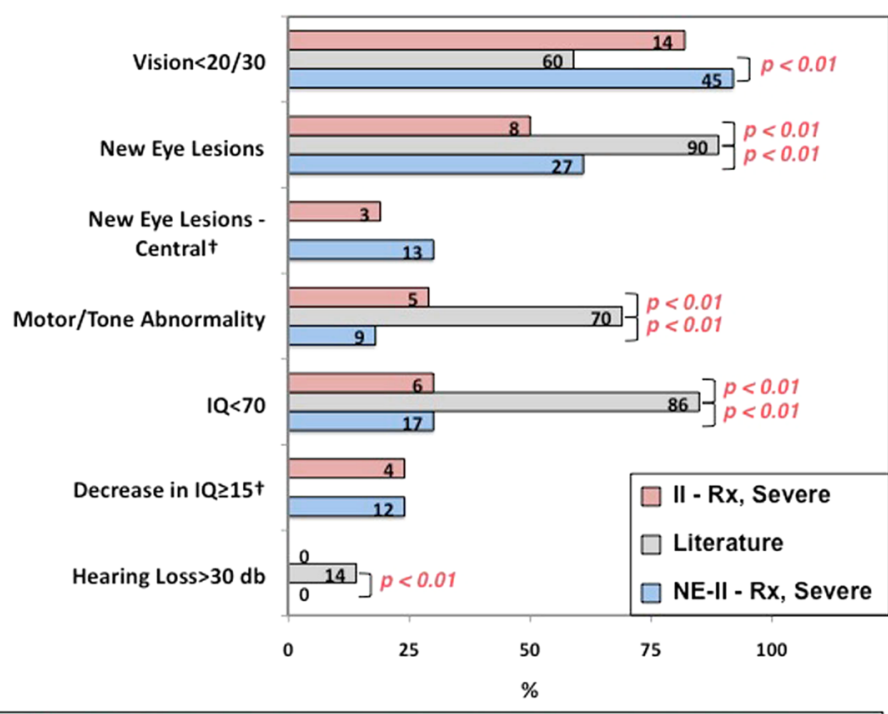

Conclusion: Endpoint outcomes of II and NE-II improved with treatment.

- Eichenwald HF. Human toxoplasmosis. Copenhagen: Munksgaard:1960. p. 41-49.

\section{Conclusions}

Effective management requires recognition of infection early during its pathogenesis to lessen the significant impact of congenital toxoplasmosis on long-term health. Prevention through detection of $T$. gondii infection in the pregnant woman facilitates treatment and is critical for optimal management. Treatment is initiated following detection of acute $T$. gondii infection in the pregnant woman through serologic testing or in the fetus due to clinical findings and confirmed by amniocentesis. Spiramycin is used to prevent infection early in fetal development. Later in development, 


\section{G Manifestations at Birth for Groups with Gestational Treatment}

\begin{tabular}{|lccccc|}
\hline & \multicolumn{2}{c}{ In Utero Rx } & No In Utero Rx & p value $\neq$ \\
& Type II & Type NE-II & Type II & Type NE-II & \\
Gestational Age $<38$ weeks & $3^{*} / 15 \dagger(20 \%)$ & $3 / 13(23 \%)$ & $15 / 37(41 \%)$ & $40 / 79(51 \%)$ & 0.82 \\
Severe, S/MN & $8 / 15(53 \%)$ & $6 / 13(46 \%)$ & $25 / 37(68 \%)$ & $71 / 80(89 \%)$ & 0.08 \\
Splenomegaly & $1 / 15(7 \%)$ & $1 / 13(8 \%)$ & $8 / 36(22 \%)$ & $36 / 78(46 \%)$ & 0.54 \\
Hepatomegaly & $4 / 15(27 \%)$ & $2 / 13(15 \%)$ & $10 / 36(28 \%)$ & $40 / 78(51 \%)$ & 0.11 \\
Skin Rash & $1 / 15(7 \%)$ & $0 / 13(0 \%)$ & $7 / 36(19 \%)$ & $29 / 78(37 \%)$ & Not Estimable \\
Chorioretinal Scars & $8 / 15(53 \%)$ & $5 / 13(38 \%)$ & $24 / 37(65 \%)$ & $67 / 80(84 \%)$ & 0.07 \\
\hline
\end{tabular}

Conclusion: Without gestational Rx, prematurity, severity, hepatomegaly, splenomegaly, skin rash, chorioretinal scars more prevalent with NE-II.

With gestational Rx, associations of NE-II with manifestations at birth no longer significant, less prevalent with NE-II.

Not Estimable $=$ due to 0 cell.

- Number of patients with manifestation at birth in each in utero treatment and parasite serotype cohort.

$\dagger$ Total number of patients in each in utero treatment and parasite serotype cohort; table only includes those diagnosed at birth anc treated during the first year of life.

$\ddagger$ Based on a test of the in utero treatment group by parasite serotype interaction from a logistic regression model. A statistically significant interaction would indicate that the effect of parasite serotype on disease manifestations depends on whether in utero treatment was received.

H

Endpoint Outcomes Based On Treatment Group

\begin{tabular}{|c|c|c|c|c|c|c|c|c|}
\hline & \multicolumn{2}{|c|}{ Type II } & \multicolumn{2}{|c|}{ Type NE-II } & \multirow[t]{2}{*}{ p-value $\ddagger$} & \multirow{2}{*}{$\begin{array}{l}\text { Type II } \\
A+C\end{array}$} & \multirow{2}{*}{$\begin{array}{c}\text { Type NE-II } \\
\qquad+C\end{array}$} & \multirow[t]{2}{*}{ p-value } \\
\hline & A & C & A & C & & & & \\
\hline Vision $<20 / 30$ & $\begin{array}{c}10 * / 19 \dagger \\
(53 \%)\end{array}$ & $\begin{array}{c}5 / 10 \\
(50 \%)\end{array}$ & $\begin{array}{l}19 / 27 \\
(70 \%)\end{array}$ & $\begin{array}{l}28 / 31 \\
(90 \%)\end{array}$ & 0.17 & $\begin{array}{l}15 / 29 \\
(52 \%)\end{array}$ & $\begin{array}{l}47 / 58 \\
(81 \%)\end{array}$ & $<0.01$ \\
\hline New eye lesions & $\begin{array}{c}5 / 17 \\
(29 \%)\end{array}$ & $\begin{array}{c}4 / 7 \\
(57 \%)\end{array}$ & $\begin{array}{c}9 / 24 \\
(38 \%)\end{array}$ & $\begin{array}{l}19 / 27 \\
(70 \%)\end{array}$ & 0.85 & $\begin{array}{c}9 / 24 \\
(38 \%)\end{array}$ & $\begin{array}{l}28 / 51 \\
(55 \%)\end{array}$ & 0.22 \\
\hline $\begin{array}{l}\text { New eye lesions - } \\
\text { central }\end{array}$ & $\begin{array}{c}2 / 17 \\
(12 \%)\end{array}$ & $\begin{array}{c}2 / 7 \\
(29 \%)\end{array}$ & $\begin{array}{c}6 / 24 \\
(25 \%)\end{array}$ & $\begin{array}{c}7 / 27 \\
(26 \%)\end{array}$ & 0.42 & $\begin{array}{c}4 / 24 \\
(17 \%)\end{array}$ & $\begin{array}{l}13 / 51 \\
(25 \%)\end{array}$ & 0.56 \\
\hline $\begin{array}{l}\text { Motor/Tone } \\
\text { Abnormality }\end{array}$ & $\begin{array}{c}3 / 19 \\
(16 \%)\end{array}$ & $\begin{array}{l}2 / 10 \\
(20 \%)\end{array}$ & $\begin{array}{c}6 / 27 \\
(22 \%)\end{array}$ & $\begin{array}{c}3 / 31 \\
(10 \%)\end{array}$ & 0.32 & $\begin{array}{c}5 / 29 \\
(17 \%)\end{array}$ & $\begin{array}{c}9 / 58 \\
(16 \%)\end{array}$ & 1.00 \\
\hline$I Q<70$ & $\begin{array}{c}2 / 19 \\
(11 \%)\end{array}$ & $\begin{array}{c}4 / 13 \\
(31 \%)\end{array}$ & $\begin{array}{l}10 / 30 \\
(33 \%)\end{array}$ & $\begin{array}{c}8 / 37 \\
(22 \%)\end{array}$ & 0.08 & $\begin{array}{c}6 / 32 \\
(19 \%)\end{array}$ & $\begin{array}{l}18 / 67 \\
(27 \%)\end{array}$ & 0.46 \\
\hline $\begin{array}{l}\text { Decrease in IQ } \\
\geq 15\end{array}$ & $\begin{array}{c}3 / 19 \\
(16 \%)\end{array}$ & $\begin{array}{l}2 / 10 \\
(20 \%)\end{array}$ & $\begin{array}{c}6 / 27 \\
(22 \%)\end{array}$ & $\begin{array}{c}6 / 31 \\
(19 \%)\end{array}$ & 0.70 & $\begin{array}{c}5 / 29 \\
(17 \%)\end{array}$ & $\begin{array}{l}12 / 58 \\
(21 \%)\end{array}$ & 0.78 \\
\hline $\begin{array}{l}\text { Hearing loss } \\
>30 \mathrm{db}\end{array}$ & \multicolumn{4}{|c|}{$\begin{array}{c}\text { There was no hearing loss in any } \\
\text { group. }\end{array}$} & $\cdot$ & $\cdot$ & $\cdot$ & $\cdot$ \\
\hline
\end{tabular}

Conclusion: Treatment dosage and endpoint outcomes not associated. Serotype and endpoint outcomes not associated.

- Number of persons with endpoint in each parasite serotype and treatment group cohort.

† Total number of persons in each parasite serotype and treatment group cohort.

$\ddagger$ Based on a test of the treatment group by parasite serotype interaction from a logistic regression model. A statistically

significant interaction would indicate that the effect of treatment on

outcome depends on parasite serotype.

$\S P$ values are from two-sided Fisher's exact tests.
$A=$ treatment of daily pyrimethamine and sulfadiazine for two months, followed by pyrimethamine on Monday, Wednesday, and Friday, and continued daily sulfadiazine for the remainder of the year of therapy. Both randomized and feasibility cohorts included.

$C=$ treatment of daily pyrimethamine and sulfadiazine for six months, followed by pyrimethamine on Monday, Wednesday, and Friday, and continued daily sulfadiazine for the remainder of the year. Both randomized and feasibility cohorts included.

\begin{tabular}{l} 
Conclusions: \\
-Endpoint outcomes for II and NE-II serotypes improve with treatment. \\
-Associations of NE-II manifestations at birth are not significant with gestational treatment. \\
-Associations are not absolute. \\
-Prompt prenatal diagnosis and treatment is likely to be especially important for those \\
with NE-II serotype, but critical for all infected persons. \\
\hline
\end{tabular}

Fig. 4 continued 
A

\section{Endpoint 1: Neurologic outcomes (motor/tone abnormality)}

Nono, Mild, Moderale Systemic Catogories Moderala Neurologic, Severe Categonles
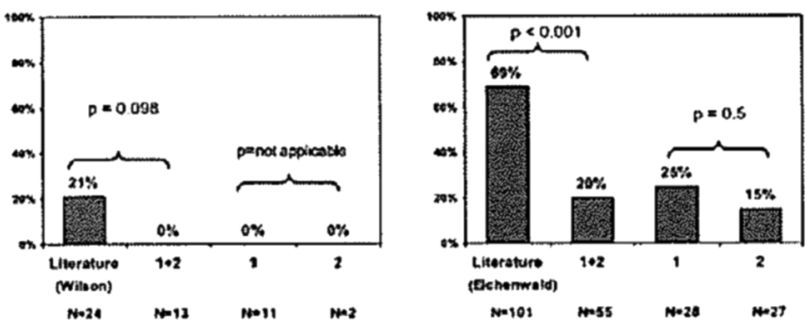

Wigon: moen aga ot ovetuation = 0 yoors

Etehonwaid: mean ape at evapjation 14 years

A

\section{Endpoint 3: Decrease in $I Q \geq 15$}

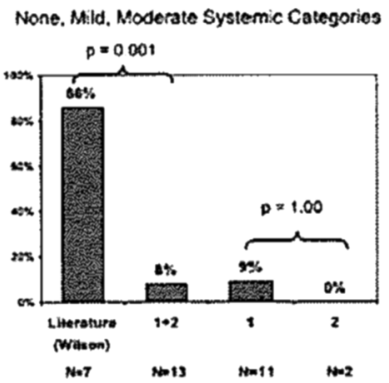

Moderate Neurologic, Severe Categories

Whison: mean age al evaivation $=8$ years Agos of Crikago evaluation 25 yeors

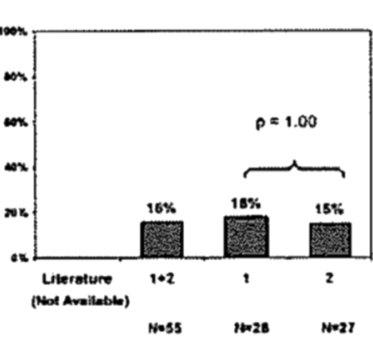

Endpoint 5: New eye lesions

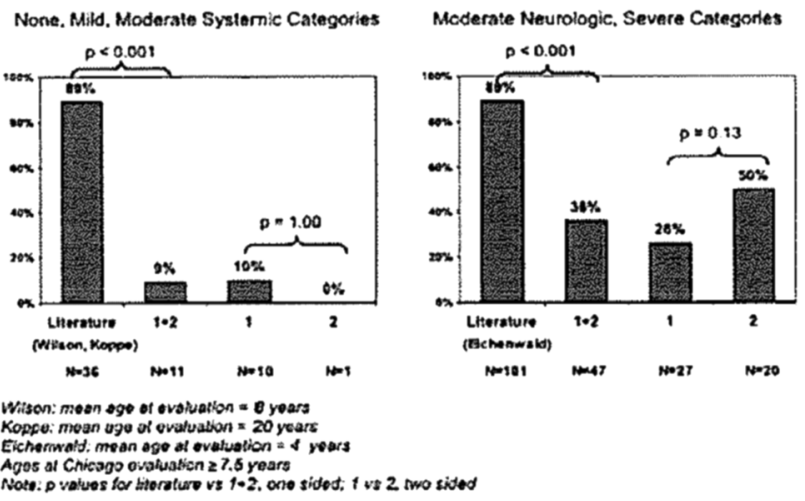

Fig. 4 continued

in infancy, or in patients with recurrent eye disease, treatment is with Pyrimethamine with Leucovorin and Sulfadiazine. The earlier the treatment is offered in each clinical setting, the more likely disease will be arrested and outcomes

\section{Endpoint 2: $1 Q<70$}
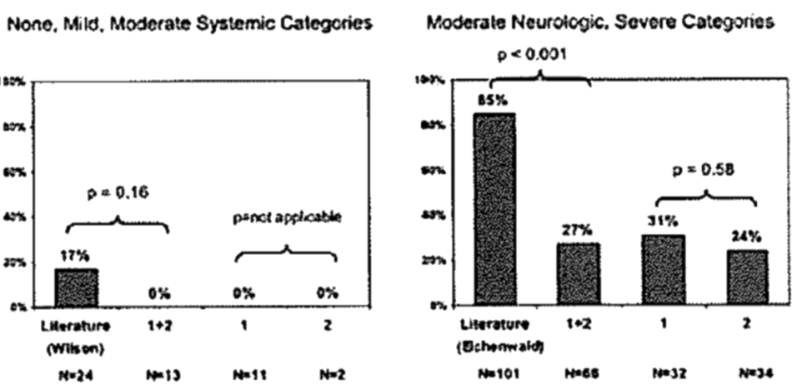

Wiscri mean ogo of ovatuotion a 0 years

Eichonwadd: moon age al ovatuation $=4$ years

\section{Endpoint 4: Vision $<20 / 30$}
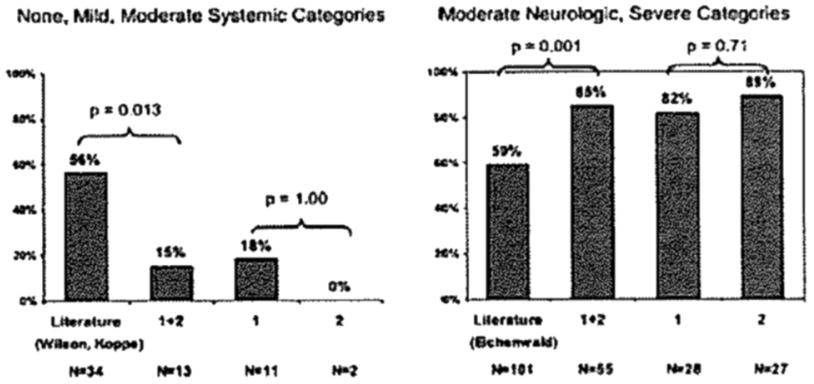

Wison: mean age at ovaluation $\approx 8$ years

Koppe: mean age at ovatuation $\times 20$ yoors

Eichoriwald: moan age at ovalustion $=4$

Hoto: $p$ vaties for therotiure vs $1 \cdot 2$, ono sided; $t$ va 2 , two sided

\section{Endpoint 6: Hearing loss $>30 \mathrm{~dB}$}

None, Mild, Moderale Systemic Calegories

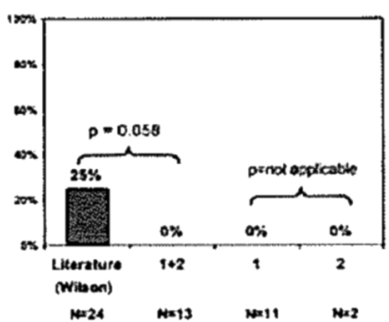

Whiton: mogn age at Gvaluation $n 8$ years Eichonwald: moan age at ovaluation $=4$ Ages at Chicapo evaluaton 25 years
Moderate Neurologic, Severe Calegories

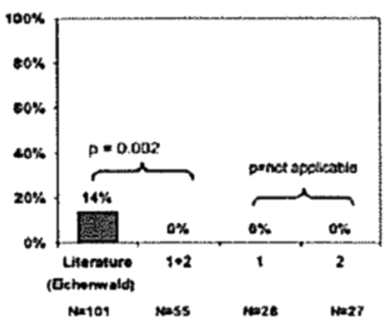

improved. This approach to early treatment also applies to ventricular shunting for hydrocephalus. Seizures respond to anti-parasitic and anti-epileptic medications. Choroidal neovascular membranes secondary to $T$. gondii infection 
B

End point $=$ vision
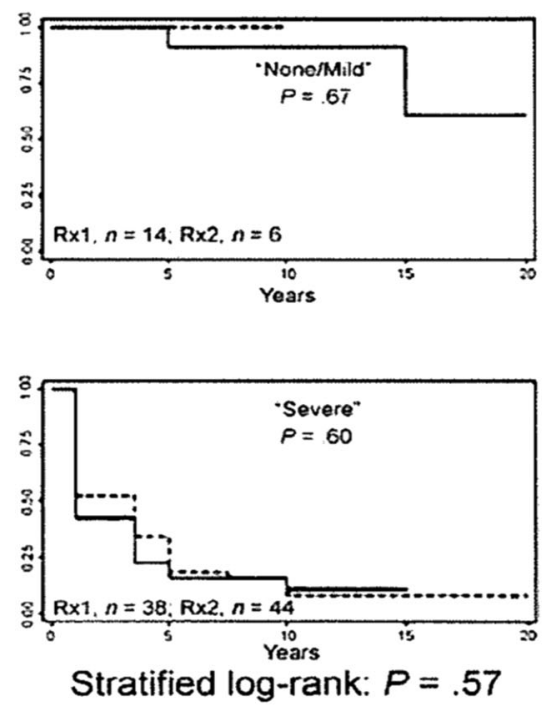

End point $=1 \mathrm{Q}<70$ points
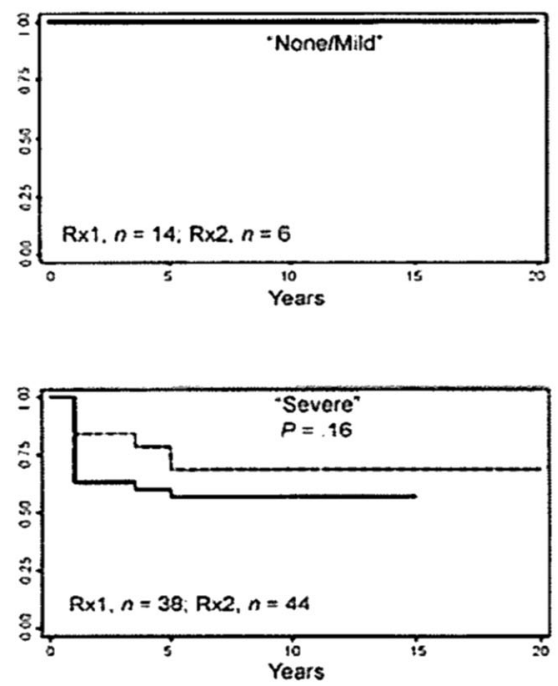

Fig. 4 continued
End point $=$ new eye lesion
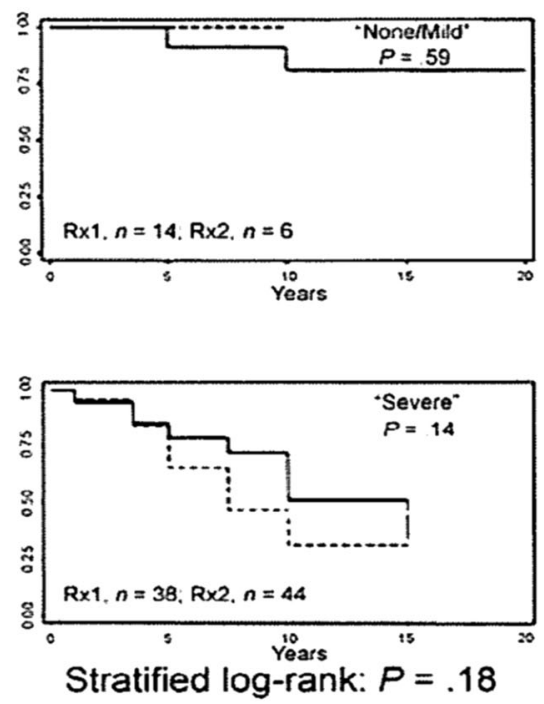

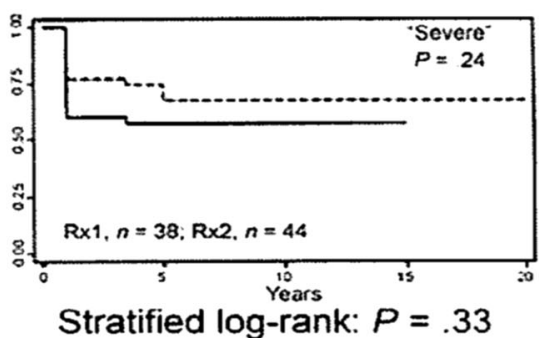

End point $=$ motor abnormality

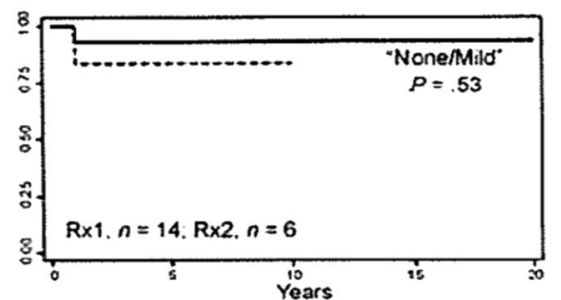

log-rank: $P=.33$

\section{End point $=$ decrease in $I Q>15$ points End point $=$ hearing loss}
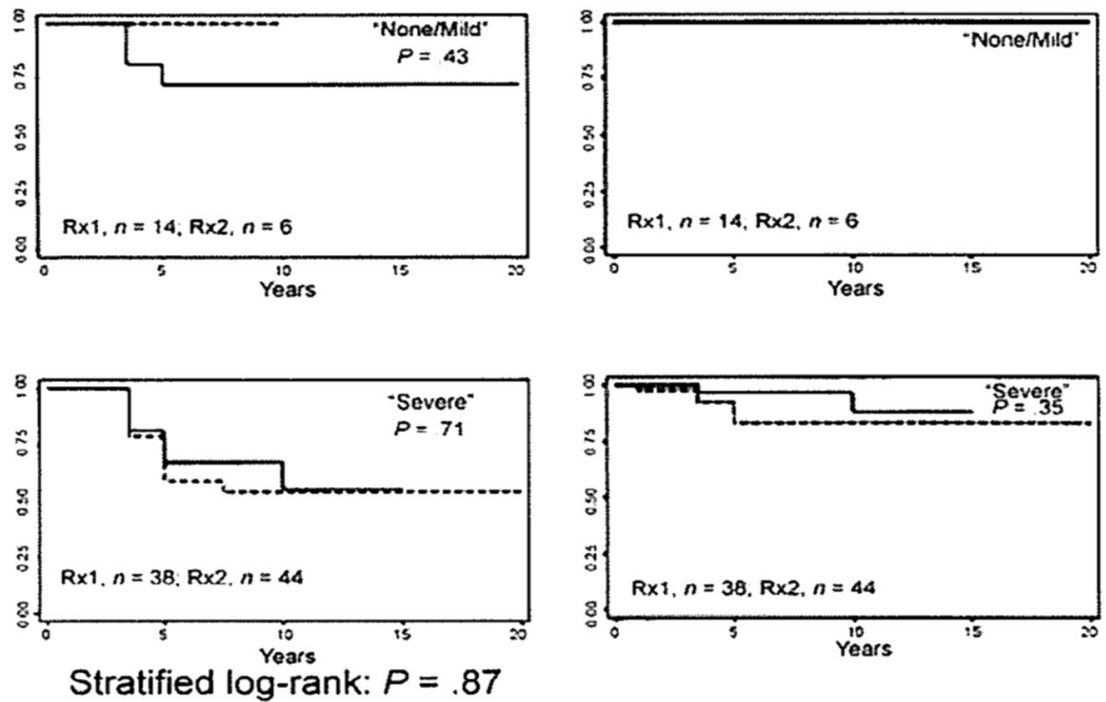

respond to treatment with $\alpha$-VEGF and anti-parasitic medicines. New medicines with less toxicity and hypersensitivity, and improved efficacy by targeting the latent stage of the parasite, will change the management of this disease markedly in the future. For the first time, there appear to be promising candidate compounds in development with these properties. Similarly, there is promise in recent work for vaccine development. Neither new medicines nor vaccines are in clinical trials at this time.

Acknowledgments We gratefully acknowledge the support of NIH R01 DMID AI 27530, the Mann and Cornwell Family, the Morel
Family, the Rooney Alden Family, The Engel family, The Samuel family and friends, The Pritzker family, The Harris family, The Mussilami Family, and the Hyatt Hotels Foundation. We are grateful for the many patients and physicians who have worked with us in the NCCCTS and have helped us to learn how to manage this infection.

Disclosure Rima McLeod, Joseph Lykins, A. Gwendolyn Noble, Peter Rabiah,, Charles N. Swisher, MD, Peter T. Heydemann, David McLone, David Frim, Shawn Withers, Fatima Clouser, and Kenneth Boyer declare that they have no conflict of interest.

Human and Animal Rights and Informed Consent This article does not contain any studies with human or animal subjects performed by any of the authors. 


\section{References}

Papers of particular interest, published recently, have been highlighted as:

- Of importance

-• Of major importance

1. Wolf A, Cowen D, Paige BH. Toxoplasmic encephalomyelitis III. A new case of ganulomatous encephalitis due to a protozoon. Am J Pathol. 1939;15:657-94.

2. Sabin AB. Toxoplasmic encephalitis in children. J Am Med Assoc. 1941;116:801-7.

3. Ajzenberg D. High burden of congenital toxoplasmosis in the United States: the strain hypothesis? Clin Infect Dis. 2012;54(11):1606-7.

4. Alford C Jr, Stagno S, Reynolds DW. Congenital toxoplasmosis: clinical, laboratory, and therapeutic considerations, with special reference to subclinical disease. Bull $N$ Y Acad Med. 1974;50:160-81.

5. Andrade GM, Vasconcelos-Santos DV, Carellos EV, Romanelli RM, Vitor RW, Carneiro AC, Januario JN. Congenital toxoplasmosis from a chronically infected woman with reactivation of retinochoroiditis during pregnancy. J Pediatr (Rio J). 2012;86(1):85-8. In Belo Horizonte, a prégnant woman who was chronically infected developed réactivation of retinochoroiditis and transmitted the infection to her fetus.

6. Avelino MM, Amaral WN, Rodrigues IM, et al. Congenital toxoplasmosis and prenatal care state programs. BMC Infect Dis. 2014;14:33.

7. Beghetto E, Buffolano W, Spadoni A, del Pezza M, di Cristina M, Minenkova O, Petersen E, Felici F, Gargano N. Diagnosis of primary $T$. gondii infection in pregnancy by an $\mathrm{IgG}$ avidity assay based on recombinant antigens. J Clin Microbiol. 2003;41: 5414-8.

8. Ben abdallah R, Siala E, Bouafsoun A, et al. Toxoplasmosis mother-to-child screening: study of cases followed in the Pasteur Institute of Tunis (2007-2010). Bull Soc Pathol Exot. 2013; 106(2):108-12.

9. Beraud L, Rabilloud M, Fleury J, Wallon M, Peyron F. Congenital toxoplasmosis: long-term ophthalmologic follow-up praised by patients. J Fr Ophtalmol. 2013;36(6):494-8.

10. Berrebi A, Bardou M, Bessieres M, et al. Outcome for children infected with congenital toxoplasmosis in the first trimester and with normal ultrasound findings: a study of 36 cases. Eur J Obstet Gynaecol Reprod Bio. 2007;135:53-7.

11. Binquet C, Wallon M, Quantin C, Kodjikian L, Garweg J, Fleury J, Peyron F, Abrahomawicz M. Prognostic factors for the long-term development of ocular lesions in 327 children with congenital toxoplasmosis. Epidemiol Infect. 2003;131:1157-68.

12. Boyer KM, Holfels E, Roizen N, et al. Risk factors for Toxoplasma gondii infection in mothers of infants with congenital toxoplasmosis: implications for prenatal management and screening. Am J Obstet Gynecol. 2005;192:564-71.

13. Brezin AP, Thulliez P, Couvreur J, et al. Ophthalmic outcome after prenatal and postnatal treatment of congenital toxoplasmosis. Am J Ophthalmol. 2003;138:779-84.

14. Bricker-Hildalgo H, Brenier-Pinchart MP, Schaal JP, et al. Value of Toxoplasma gondii detection in one hundred thirtythree placentas for the diagnosis of congenital toxoplasmosis. Pediatr Infect Dis J. 2007;26:845-6.

15. Buffolano W, Beghetto E, Del Pezzo M, Spadoni A, Di Cristina M, Petersen E, Gargano N, (Submitted). Neonatal diagnosis of congenital toxoplasmosis using an enzyme-linked IgM capture assay with a combination of recombinant antigens.
16. Burg JL, Perelman L, Kasper LH, Ware PL, Boothroyd JC. Molecular analysis of the gene encoding the major surface antigen of Toxoplasma gondii. J. Immunol. 1988;141:3584-91.

17. $\bullet$ Burrowes D, Boyer K, Swisher CN, et al. Spinal cord lesions in Congenital Toxoplasmosis demonstrated with neuroimaging, including their successful treatment in an adult. J Neuroparasitology. 2012;3(2012):1-15. Spinal cord T2 weighted abnormalities on MRI caused neurologic symptoms for a middle aged congenitally infected person. These symptoms and signs resolved with treatment for her Toxoplasma.

18. Chapey E, Wallon M, Debize G, Rabilloud M, Peyron F. Diagnosis of congenital toxoplasmosis by using a whole-blood gamma interferon release assay. J Clin Microbiol. 2010; 48(1):41-5.

19. Chiang E, Goldstein DA, Shapiro MJ, Mets MB. Branch retinal artery occlusion caused by toxoplasmosis in an adolescent. Case Report Ophthalmol. 2012;3(3):333-8.

20. Cinalli G, Sainte-Rose C, Chumas P, et al. Failure of third ventriculostomy in the treatment of aqueductal stenosis in children. Neurosurg Focus. 1999;6(4):e3.

21. Cortina-Borja M, Tan HK, Wallon M, et al. Prenatal treatment for serious neurological sequelae of congenital toxoplasmosis: an observational prospective cohort study. PLoS Med. 2010;7(10):1-11.

22. - Costa JG, Carneiro AC, Tavares AT, et al. Real-time PCR as a prognostic tool for human congenital toxoplasmosis. J Clin Microbiol. 2013;51(8):2766-8. Increased amniotic fluid parasite burden detected by real time qPCR is associated with worse pognosis.

23. Couvreur J. Étude de la toxoplasmose congenitale à propo de 20 observation. Paris: These; 1955.

24. Couvreur J, Desmonts G. Congenital and maternal toxoplasmosis. A review of 300 cases. Develop. Med. Chld. Neurol. 1962;4:519-30.

25. Couvreur J, Desmonts G, Late evolutive outbreaks of congenital toxoplasmosis. Cah Coll Med Hop Paris. 1964;115:752-8, French.

26. Couvreur J, Desmonts G, Girre JY. Congenital toxoplasmosis in twins: a series of 14 pairs of twins: absence of infection in one twin in two pairs. J Pediatr. 1976;89(2):235-40.

27. Couvreur J, Desmonts G, Aron-Rosa D. Le prognostic oculare de la toxoplasmose congenitale: role du traitement. Ann Pediatr. 1984;31(10):855-858.

28. Couvreur J, Desmonts G, Thulliez P. Prophylaxis of congenital toxoplasmosis. Effects of spiramycin on placental infection. J Antimicrob Chemother. 1988;22:193-200.

29. Couvreur J, Thulliez P, Daffos F, Aufrant C, Bompard Y, Gesquiere A, Desmonts G. In utero treatment of toxoplasmic fetopathy with the combination Pyrimethamine-Sulfadiazine. Fetal Diagn Ther. 1993;8(1):45-50.

30. Couvreur J, Thulliez P. Acquired toxoplasmosis with ocular or neurologic involvement. Presse Med. 1996;25:438-42.

31. Daffos F, Forestier F, Capella-Pavlovsky M, et al. Prenatal management of 746 pregnancies at risk for congenital toxoplasmosis. N Engl J Medicine. 1988;318:271-5.

32. Dannemann BR, Vaughan WC, Thulliez P, Remington JS. Differential agglutination test for diagnosis of recently acquired infection with Toxoplasma gondii. J Clin Microbiol. 1990;28:1928-33.

33. Decoster A, Darcy F, Caron A, Vinatier D, Houze de L'Aulnoit D, Vittu G, Niel G, Heyer F, Lecolier B, Delcroix M. Anti-P30 IgA antibodies as prenatal markers of congenital toxoplasma infection. Clin Exp Immunol. 1992;87:310-5.

34. Delair E, Monnet D, Grabar S, Dupouy-Camet J, Yera H, Brezin AP. Respective rôles of acquired and congénital infections in presumed ocular toxoplasmosis. Am J Ophthalmol. 2008; 146(6):851-5. 
35. •• Delair E, Latkany P, Noble AG, et al. Clinical manifestations of ocular toxoplasmosis. Ocul Immunol Inflamm. 2011;19(2): 91-102. In depth, state of the art, description of ocular toxoplasmosis and its treatment. Severe toxoplasmosis occurs in Guyana.

36. Desmonts G, Couvreur J. Toxoplasmosis in pregnancy and its transmission to the fetus. Bull N Y Acad Med. 1974;50:146-59.

37. - Lago EG, Oliveira AP, Bender AL, Presence and duration of anti-Toxoplasma gondii immunoglobulin $\mathrm{M}$ in infants with congenital toxoplasmosis. J Pediatr (Rio J). [Epub ahead of print] 2014; IgM specific for T. gondii is useful for diagnosis of congenital toxoplasmosis in Porto Allegre but this test is not sensitive enough to be completely effective in making this diagnosis.Utility and limitations discussed in accompanying editorial by McLeod.

38. Desmonts G, Couvreur J. Congenital toxoplasmosis: a prospective study of the offspring of 542 women who acquired toxoplasmosis during pregnancy. In: Thalhammer, O., Pollak, A., Baumgarten, K., Eds. Pathophysiology of congenital disease: perinatal medicine, 6th European Congress, Vienna. Stuttgart Georg Thieme Publishers; 1979, pp. 51-60.

39. Desmonts G, Remington JS. Direct agglutination test for diagnosis of Toxoplasma infection: method for increasing sensitivity. J Clin Microbiol. 1980;11:562-8.

40. Desmonts G. Acquired toxoplasmosis in pregnant women. Evaluation of the frequency of transmission of Toxoplasma and of congenital toxoplasmosis. Lyon Medical. 1982;248:115-23.

41. Desmonts G, Couvreur J. Congenital toxoplasmosis. Prospective study of the outcome of pregnancy in 542 women with toxoplasmosis acquired during pregnancy. Ann Pediatr (Paris). 1984;31:805-9.

42. • De souza-e-silva CH, Vasconcelos-santos DV, De Andrade $\mathrm{GQ}$, et al. Association between IgG subclasses against Toxoplasma gondii and clinical signs in newborns with congenital toxoplasmosis. Pediatr Infect Dis J. 2013;32(1):13-6. IgG subclass of antibody to T. gondii associates with clinical signs in newborns with congenital toxoplasmosis in Brazil.

43. Dorfman RF, Remington JS. Value of lymph-node biopsy in the diagnosis of acute toxoplasmosis. N Engl J Med. 1973;289: 878-81.

44. Eichenwald HF. Congenital toxoplasmosis: a study of 150 cases. Am. J. Dis. Chld. 1957;94:411-2.

45. Eichenwald HF. A study of congenital toxoplasmosis, with particular emphasis on clinical manifestations, sequelae and therapy. In: Siim J, editor. Human toxoplasmosis. Copenhagen: Munksgaard; 1960. p. 41-9.

46. Fayyaz H, Rafi J. TORCH screening in polyhydramnios: an observational study. J Matern Fetal Neonatal Med. 2012; 25(7):1069-72.

47. Feldman HA. Congenital toxoplasmosis-a study of 103 cases. Am J Dis Child. 1953;86:487.

48. • Ferguson DJ, Bowker C, Jeffery KJ, Chamberlain P, Squier W. Congenital toxoplasmosis: continued parasite proliferation in the fetal brain despite maternal immunological control in other tissues. Clin Infect Dis. 2013;56(2):204-8. T. gondii replicates in the fetal brain when controlled in other tissues.

49. Ferrandiz J, Mercier C, Wallon M, Picot S, Cesbron-Delauw MF, Peyron F. Limited value of assays using detection of immunoglobulin $\mathrm{G}$ antibodies to the two recombinant dense granule antigens, GRA1 and GRA6 Nt of Toxoplasma gondii, for distinguishing between acute and chronic infections in pregnant women. Clin Diagn Lab Immunol. 2004;11:1016-21.

50. Foulon W, Villena I, Stray-Pedersen B, et al. Treatment of toxoplasmosis during pregnancy: a multicenter study of impact on fetal transmission and children's sequelae at age 1 year. Am J Obstet Gynecol. 1999;180:410-5.
51. Frenkel JK, Friedlander S. Toxoplasmosis: pathology of neonatal disease, pathogenesis, diagnosis and treatment, USA Government Printing Office, Washington, Publication n 141. US Public Health Service; 1951. p. 107.

52. Fricker-hidalgo H, Cimon B, Chemla C, et al. Toxoplasma seroconversion with negative or transient immunoglobulin $\mathrm{M}$ in pregnant women: myth or reality? A French multicenter retrospective study. J Clin Microbiol. 2013;51(7):2103-11.

53. Guerina NG, Hsu HW, Meissner HC, Maguire JH, Lynfield R, Stechenberg B, Abroms I, Pasternack MS, Hoff R, Eaton RB. Neonatal serologic screening and early treatment for congenital T. gondii infection. The New England Regional Toxoplasma Working Group. N Engl J Med. 1994;330:1858-63.

54. Hedman K, Lappalainen M, Söderlund M, Hedman L. Avidity of $\mathrm{IgG}$ in serodiagnosis of infectious diseases. Rev Med Microbiol. 1993;4:123-9.

55. Hohlfeld P, Daffos F, Thulliez P, et al. Fetal toxoplasmosis: outcome of pregnancy and infant follow-up after in utero treatment. J Pediatr. 1989;115(5 Pt 1):765-9.

56. Hohlfeld P, Daffos F, Costa JM, et al. Prenatal diagnosis of congenital toxoplasmosis with a polymerase-chain-reaction test on amniotic fluid. N Engl J Med. 1994;331(11):695-9.

57. Jenum PA, Stray-Pedersen B, Gundersen AG. Improved diagnosis of primary $T$. gondii infection in early pregnancy by determination of anti-toxoplasma immunoglobulin $G$ avidity. J Clin Microbiol. 1997;35:1972-7.

58. Jenum PA, Stray-Pedersen B. Development of specific immunoglobulins G, M and A following primary $T$. gondii infection in pregnant women. J Clin Microbiol. 1998;36:2907-13.

59. Jones JL, Roberts JM. Toxoplasmosis hospitalizations in the United States, 2008, and trends, 1993-2008. Clin Infect Dis. 2012;54(7):e58-61.

60. Kasper LH, Ware PL. Identification of stage specific antigens of Toxoplasma gondii. Infect Immun. 1989;57:688-92.

61. Kimball AC, Kean BH, Fuchs F. Congenital toxoplasmosis: a prospective study of 4,048 obstetric patients. Am J Obstet Gynaecol. 1971;111:211-8.

62. Kieffer F, Wallon M, Garcia P, et al. Risk factors for retinochoroiditis during the first 2 years of life in infants with treated congenital toxoplasmosis. Pediatr Infect Dis J. 2008;27(1):27-32.

63. - Kieffer F, Wallon M. Congenital toxoplasmosis. Handb Clin Neurol. 2013;112:1099-101. Treatment of congenital toxoplasmosis described.

64. Kong JT, Grigg ME, Uyetake L, Parmley S, Boothroyd JC. Serotyping of Toxoplasma gondii infections in humans using synthetic peptides. J Infect Dis. 2003;187(9):1484-95.

65. Koppe JG, Kloosterman GJ. Congenital toxoplasmosis: longterm follow-up. Padiatr Padol. 1982;17:171-9.

66. Koppe JG, Loewer-Sieger DH, de Roever-Bonnet H. Results of 20-year follow-up of congenital toxoplasmosis. Lancet. 1986; 1(8475):254-6.

67. Kortbeek LM, Hofhuis A, Nijhuis CD, Havelaar AH. Congenital toxoplasmosis and DALYs in the Netherlands. Mem Inst Oswaldo Cruz. 2009;104(2):370-3.

68. - Maenz M, Schlüter D, Liesenfeld O, Schares G, Gross U, Pleyer U. Ocular toxoplasmosis past, present and new aspects of an old disease. Prog Retin Eye Res. 2014;39:77-106. Review of ocular toxoplasmosis and the role of strain.

69. Lecordier L, Fourmaux MP, Mercier C, Dehecq E, Masy E, Cesbron-Delauw MF. Enzyme-linked immunosorbent assays using the recombinant dense granule antigens GRA6 and GRA1 of $T$. gondii for detection of immunoglobulin $\mathrm{G}$ antibodies. Clin Diagn Lab Immunol. 2000;7:607-11.

70. • L'Ollivier C, Wallon M, Faucher B, Piarroux R, Peyron F, Franck J. Comparison of mother and child antibodies that target 
high-molecular-mass Toxoplasma gondii antigens by immunoblotting improves neonatal diagnosis of congenital toxoplasmosis. Clin Vaccine Immunol. 2012;19(8):1326-8. Important in diagnosis of congenital toxoplasmosis using differences between bands in serum from mother and child in Western Blot.

71. McAuley J, Boyer KM, Patel D, Mets M, Swisher C, Roizen N, Wolters C, Stein L, Stein M, Schey W. Early and longitudinal evaluations of treated infants and children and untreated historical patients with congenital toxoplasmosis: The Chicago collaborative treatment trial. Clin Infect Dis. 1994;18:38-72.

72. McLeod R, Beem MO, Estes RG. Lymphocyte anergy specific to Toxoplasma gondii antigens in a baby with congenital toxoplasmosis. J Clin Lab Immunol. 1985;17:149-53.

73. McLeod R, Mack DG, Boyer K, et al. Phenotypes and functions of lymphocytes in congenital toxoplasmosis. J Lab Clin Med. 1990;116(5):623-35.

74. McLeod R, Mack D, Foss R, et al. Levels of Pyrimethamine in sera and cerebrospinal and ventricular fluids from infants treated for congenital toxoplasmosis. Antimicrob Agents Chemother. 1992;36:1040-8.

75. McLeod R, Boyer K, Roizen N, Stein L, Swisher C, Holfels E, Hopkins J, Mack D, Karrison T, Patel D, Pfiffner L, Remington J, Withers S, Meyers S, Aitchison V, Mets M, Rabiah P, Meier P. The child with congenital toxoplasmosis. Curr Clin Top Infect Dis. 2000;20:189-208.

76. McLeod R, Boyer K, Karrison T, Kasza K, Swisher C, Roizen N, Jalbrzikowski J, Remington J, Heydemann P, Noble AG, Mets M, Holfels E, Withers S, Latkany P, Meier P; Toxoplasmosis Study Group, Outcome of treatment for congenital toxoplasmosis, 1981-2004: the National Collaborative ChicagoBased, Congenital Toxoplasmosis Study. Clin Infect Dis 2006a; 42:1383-94. Epub 2006 Apr 11

77. McLeod R, Khan AR, Noble GA, et al. Severe Sulfadiazine hypersensitivity in a child with reactivated congenital toxoplasmic chorioretinitis. Pediatr Infect Dis J. 2006;25(3):270-2.

78. McLeod R, Kieffer F, Sautter M, Hosten T, Pelloux H. Why prevent, diagnose and treat congenital toxoplasmosis? Mem Inst Oswaldo Cruz. 2009;104:320-44.

79. •• McLeod R, Boyer KM, Lee D, Mui E, Wroblewski K, Karrison T, Noble AG, Withers S, Swisher CN, Heydemann PT, Sautter M, Babiarz J, Rabiah P, Meier P, Grigg ME, Toxoplasmosis Study Group. Prematurity and severity are associated with Toxoplasma gondii alleles (NCCCTS, 1981-2009). Clin Infect Dis. 2012;54(11):1595-605. Defines differences in genetics of parasites detected with serotyping, and associations of serotypes of parasites with prematurity and greater severity of disease. Both type 2 and not type 2 respond to treatment with Pyrimethamine and Sulfadiazine.

80. $\bullet$ McLeod R, Lee D, Boyer K. Toxoplasmosis in the fetus and newborn infant. State of the art update; 2014a in press.

81. • McLeod R, Lee D, Boyer K. Diagnosis of congenital toxoplasmosis: a practical procedural atlas. Complete state of the art procedural atlas. Valuable details; 2014b in press.

82. - McLeod R. Utility and limitations of $T$. gondii-specific IgM serum antibodies in the diagnosis of congenital toxoplasmosis in Porto Alegre. J Pediatr (Rio J); 2014. [Epub ahead of print]. Discuss utility and limitations of IgM assay for T. gondii infection in newborn infants in Porto Alegre.

83. Mets M, Holfels E, Boyer KM, et al. Eye manifestations of congenital toxoplasmosis. Am J Ophthalmol. 1996;122:309-24.

84. - Mohamed, S, Osman, A, Al jurayyan, NA, Al nemri, A, Salih, MA. Congenital toxoplasmosis presenting as central diabetes insipidus in an infant: a case report. BMC Res Notes. 2014;7(1):184. Diabetes insipidus in an infant with congenital toxoplasmosis.
85. - Moncada PA, Montoya JG. Toxoplasmosis in the fetus and newborn: an update on prevalence, diagnosis and treatment. Expert Rev Anti Infect Ther. 2012; 10(7):815-28. Updated review of congenital toxoplasmosis.

86. Montoya JG, Remington JS. Management of Toxoplasma gondii infection during pregnancy. Clin Infect Dis. 2008;47(4):554-66.

87. *Morin L, Lobry JR, Peyron F, Wallon M. Seasonal variations in acute toxoplasmosis in pregnant women in the Rhône-Alpes region (France). Clin Microbiol Infect. 2012;18(10):E401-3. Models of $T$. gondii infection needed in France.

88. Neto EC, Rubin R, Schulte J, Giugliani R. Newborn screening for congenital infectious diseases. Emer Infect Dis. 2004;10: 1069-73.

89. Nogareda F, Le strat Y, Villena I, De Valk H, Goulet V. Incidence and prevalence of Toxoplasma gondii infection in women in France, 1980-2020: model-based estimation. Epidemiol Infect. 2013;14:1-10.

90. Olariu T, Remington S, McLeod R, Alam A, Montoya J. Severe congenital toxoplasmosis in the United State: clinical and serologic findings in untreated infants. Pediatr Infect Dis J. 2011;30(12):1056-61.

91. - Olariu TR, Remington JS, Montoya JG. Polymerase chain reaction in cerebrospinal fluid for the diagnosis of congenital toxoplasmosis. Pediatr Infect Dis J; 2014. [Epub ahead of print]. PCR diagnosis of T. gondii in CSF presented from the U.S. reference laboratory.

92. Samuel BU, Hearn B, Mack D, Wender P, Rothbard J, Kirisits MJ, Mui E, Wernimont S, Roberts CW, Muench SP, Rice DW, Prigge ST, Law AB, McLeod R. Delivery of antimicrobials into parasites. Proc Natl Acd Sci USA. 2003;100(24):14281-6.

93. Patel DV, Holfels EM, Vogel NP, et al. Resolution of intracranial calcifications in infants with treated congenital toxoplasmosis. Radiology. 1996;199(2):433-40.

94. •• Peyron F, Garweg JG, Wallon M, et al. Long-term impact of treated congenital toxoplasmosis on quality of life and visual performance. Pediatr Infect Dis J. 2011;30(7):597-600. Treatment of congenital toxoplasmosis improves quality of life and vision.

95. Phan L, Kasza K, Jalbrzikowski J, et al. Longitudinal study of new eye lesions in treated congenital toxoplasmosis. Ophthalmology. 2008;115(3):553-9.

96. Phan L, Kasza K, Jalbrzikowski J, et al. Longitudinal study of new eye lesions in children with toxoplasmosis who were not treated during the first year of life. Am J Ophthalmol. 2008;146(3):375-84.

97. • Prusa AR, Kasper DC, Olischar M, Husslein P, Pollak A, Hayde M. Evaluation of serological prenatal screening to detect Toxoplasma gondii infections in Austria. Neonatology. 2013;103(1): 27-34. Serologic screening prentalla in Austria is described.

98. • Remington JS, McLeod R, Thulliez P, Desmonts G. Toxoplasmosis. In: Remington J, Klein J, editors. Infectious diseases of the fetus and newborn infant, 7th Ed. Philadelphia: WB Saunders; 2011. State of the art presentation of all aspects of congenital toxoplasmosis in the fetus and newborn infant.

99. Renier D, Sainte-Rose C, Pierre-Kahn A, Hirsch JF. Prenatal hydrocephalus: outcome and prognosis. Childs Nerv Syst. 1988;4(4):213-22.

100. Robert-gangneux F. It is not only the cat that did it: how to prevent and treat congenital toxoplasmosis. J Infect. 2014; 68(Suppl 1):S125-33.

101. Roizen N, Swisher CN, Stein MA, et al. Neurologic and developmental outcome in treated congenital toxoplasmosis. Pediatrics. 1995;95:11-20.

102. Roizen N, Kasza K, Karrison T, et al. Impact of visual impairment on measures of cognitive function for children with 
congenital toxoplasmosis: implications for compensatory intervention strategies. Pediatrics. 2006;118:e379-90.

103. Romand S, Chosson M, Franck J, et al. Usefulness of quantitative polymerase chain reaction in amniotic fluid as early prognostic marker of fetal infection with Toxoplasma gondii. Am J Obstet Gynecol. 2004;190:797-802.

104. Salviz M, Montoya JG, Nadol JB, Santos F. Otopathology in congenital toxoplasmosis. Otol Neurotol. 2013;34(6):1165-9.

105. Saxon SA, Knight W, Reynolds DW, Stagno S, Alford CA. Intellectual deficits in children born with subclinical congenital toxoplasmosis: a preliminary report. J Pediatr. 1973;85(5): 792-7.

106. Siala E, Ben abdallah R, Laouiti F, et al. Toxoplasmic infections in pregnancy: About 94 cases diagnosed at the Pasteur Institute of Tunis. Gynecol Obstet Fertil. 2014;42(5):312-6.

107. Stepick-Biek P, Thulliez P, Araujo FG, Remington JS. IgA antibodies for diagnosis of acute congenital and acquired toxoplasmosis. J Infect Dis. 1990;162(1):270-3.

108. Teixeira LE, Kanunfre KA, Shimokawa PT, et al. The performance of four molecular methods for the laboratory diagnosis of congenital toxoplasmosis in amniotic fluid samples. Rev Soc Bras Med Trop. 2013;46(5):584-8.

109. Thulliez P. Commentary: efficacy of prenatal treatment for toxoplasmosis: a possibility that cannot be ruled out. Int J Epidemiol. 2001;30:1315-6.

110. Thulliez P. Maternal and foetal infection. In: Wreghitt TG, Joynson DHM, editors. Toxoplasmosis: a comprehensive clinical guide. Cambridge: Cambridge University Press; 2001. p. 193-213.

111. Toporovski J, Romano S, Hartmann S, Benini W, Chieffi PP. Nephrotic syndrome associated with toxoplasmosis: report of seven cases. Rev Inst Med Trop Sao Paulo. 2012;54(2):61-4.

112. - Vasconcelos-Santos DV, Queiroz Andrade GM. Geographic differences in outcomes of congenital toxoplasmosis. Pediatr Infect Dis J. 2011;30(9):816-17 There are geographic differences in outcomes of congenital toxoplasmosis.

113. Vasconcelos-Santos DV. Ocular manifestations of systemic disease: toxoplasmosis. Curr Opin Ophthalmol. 2012;23(6): 543-50. Review of ocular manifestations of toxoplasmosis with a focus on disease in Brazil.

114. Vogel N, Kirisits M, Michael E, Bach H, Hostetter M, Boyer K, Simpson R, Holfels E, Hopkins J, Mack D, Mets MB, Swisher CN, Patel D, Roizen N, Stein L, Stein M, Withers S, Mui E, Egwuagu C, Remington J, Dorfman R, McLeod R. Congenital toxoplasmosis transmitted from an immunologically competent mother infected before conception. Clin Infect Dis. 1996;23:1055-60.

115. Wallon M, Cozon G, Ecochard R, Lewin P, Peyron F. Serological rebound in congenital toxoplasmosis: long-term followup of 133 children. Eur J Pediatr. 2001;160:534-40.

116. Wallon M, Kodjikian L, Binquet C, et al. Long-term ocular prognosis in 327 children with congenital toxoplasmosis. Pediatr. 2004;113:1567-72.

117. Wallon M, Franck J, Thulliez P, Huissoud C, Peyron F, GarciaMeric P, Kieffer F. Accuracy of real-time polymerase chain reaction for Toxoplasma gondii in amniotic fluid. Obstet Gynecol. 2010;115:727-33.

118. Perkins ES, Smith CH, Schofield PB. Treatment of uveitis with Pyrimethamine (Daraprim). Br J Ophthalmol. 1956;40:577-86.

119. - Wallon M, Kieffer F, Binquet C, Thulliez P, Garcia-Meric P, Dureau P, Franck J, Peyron F, Bonnin A, Villena I, BonithonKopp C, Gouyon JB, Masson S, Felin A, Cornu C. Congenital toxoplasmosis: randomized comparison of strategies for retinochoroiditis prevention. Therapie. 2011;66(6):473-80. Presents methodology of an ongoing study of determination of time of treatment on late ocular toxoplasmosis.
120. $\bullet$ Wallon M, Peyron F, Cornu C, Vinault S, Abrahamowicz M, Bonithon Kopp C, Binquet C. Congenital Toxoplasma infection: monthly prenatal screening decreases transmission rate and improves clinical outcome at 3 years. Clin Infect Dis. 2013;56(9):1223-31. Frequent prenatal screening (monthly) and rapid treatment improves clinical outcome at 3 years.

121. $\bullet$ Hotop A, Hlobil H, Gross U. Efficacy of rapid treatment initiation following primary Toxoplasma gondii infection during pregnancy. Clin Infect Dis. 2012;54(11):1545-52. Screening and treatment program used in Germany with rapid integration of Pyrimethamine and Sulfadiazine effectively prevents and treats congenital toxoplasmosis in the fetus.

122. - Wallon M, Garweg JG, Abrahamowicz M, et al. Ophthalmic outcomes of congenital toxoplasmosis followed until adolescence. Pediatrics. 2014;133(3):e601-8. Follow up of ocular findings for children later in life.

123. • Stillwaggon E, Carrier CS, Sautter M, McLeod R. Maternal serologic screening to prevent congenital toxoplasmosis: a decision-analytic economic model. PLoS Negl Trop Dis. 2011;5(9):e1333. Cost benefit model for evaluation of gestational serologic screening of the present world for prevention of congenital toxoplasmosis. Cost benefit from screening in North America is favorable this model.

124. Swisher CN, Boyer K, McLeod R, The Toxoplasmosis Study Group. Congenital toxoplasmosis. Semin Pediatr Neurol. 1994;1(1):4-25.

125. Carme B, Bissuel F, Ajzenberg D, Bouyne R, Aznar C, Demar M, Bichat S, Louvel D, Bourbigot AM, Peneau C, Neron P, Dardé ML. Severe acquired toxoplasmosis in immunocompetent adult patients in French Guiana. J Clin Microbiol. 2002; 2002(40):4037-44.

126. Carme B, Demar M, Ajzenberg D, Dardé ML. Severe acquired toxoplasmosis caused by wild cycle of Toxoplasma gondii, French Guiana. Emerg Infect Dis. 2009;15:656-8.

127. Carneiro AC, Andrade GM, Costa JG, Pinheiro BV, Vasconcelos-Santos DV, Ferreira AD, Su C, Januário JN, Vitor RW. Genetic characterization of Toxoplasma gondii revealed highly diverse genotypes from human congenital toxoplasmosis in southeastern Brazil. J Clin Microbiol. 2013;51(3):901-7 Epub 2013 Jan 2.

128. Capobiango JD, Mitsuka breganó R, Navarro IT, et al. Congenital toxoplasmosis in a reference center of Paraná, Southern Brazil. Braz J Infect Dis; 2014 [Epub ahead of print].

129. - Carellos EV, De Andrade GM, Vasconcelos-santos DV, et al. Adverse socioeconomic conditions and oocyst-related factors are associated with congenital toxoplasmosis in a populationbased study in Minas Gerais, Brazil. PLoS One. 2014; 9(2):e88588. In Minas Gerais, Brazil, adverse socioeconomic conditions and oocyst related factors are associated with congenital toxoplasmosis.

130. - Carneiro AC, Andrade GM, Costa JG, et al. Genetic characterization of Toxoplasma gondii revealed highly diverse genotypes for isolates from newborns with congenital toxoplasmosis in southeastern Brazil. J Clin Microbiol. 2013;51(3):901-7. In Southeastern Brazil, there are diverse genotypes causing congenital toxoplasmosis in newborns.

131. Darde ML, Villena I, Pinon JM, Beguinot I. Severe toxoplasmosis causd by a Toxoplasma gondii strain with a new isoenzyme type acquired in French Guyana. J Clin Microbiol. 1998;1:324.

132. Demar M, Ajzenberg D, Maubon D, Djossou F, Panchoe D, Punwasi W, Valery N, Peneau C, Daigre JL, Aznar C, Cottrelle B, Terzan L, Dardé ML, Carme B. Fatal outbreak of human toxoplasmosis along the Maroni River: epidemiological, clinical, and parasitological aspects. Clin Infect Dis. 2007;45:e88-95. 
133. •• Demar M, Hommel D, Djossou F, Peneau C, Boukhari R, Louvel D, Bourbigot AM, Nasser V, Ajzenberg D, Darde ML, Carme B. Acute toxoplasmoses in immunocompetent patients hospitalized in an intensive care unit in French Guiana. Clin Microbiol Infect. 2012; 18,E221-31.

134. •• Dubey JP, Ferreira LR, Martins J, McLeod R. Oral oocystinduced mouse model of toxoplasmosis: effect of infection with Toxoplasma gondii strains of different genotypes, dose, and mouse strains (transgenic, out-bred, in-bred) on pathogenesis and mortality. Parasitology. 2012a;139(1):1-13. Identifying virulence of peroral oocyst infection of differing strains in mice. Outcomes are influenced by parasite and host genetics in these murine models of oocyst infection.

135. - Dubey JP, Lago EG, Gennari SM, Su C, Jones JL. Toxoplasmosis in humans and animals in Brazil: high prevalence, high burden of disease, and epidemiology. Parasitology. 2012c;139(11):1375-424. T. gondii infections in brazil are of high prevalence and cause significant disease.

136. - Dubey JP, Dennis PM, Verma SK, et al. Epidemiology of toxoplasmosis in white tailed deer (Odocoileus virginianus): Occurrence, congenital transmission, correlates of infection, isolation, and genetic characterization of Toxoplasma gondii. Vet Parasitol. 2014. [Epub ahead of print] Epidemics of T. gondii infection have occurred recently in association with consumption of deer meat. The infection in white tail deer is described in this work.

137. Grigg ME, Ganatra J, Boothroyd JC, Margolis TP. Unusual abundance of atypical strains associated with human ocular toxoplasmosis. J Infect Dis. 2001;184:633-9.

138. Halsby K, Guy E, Said B, et al. Enhanced surveillance for toxoplasmosis in England and Wales, 2008-2012. Epidemiol Infect. 2013;7:1-8.

139. Khan A, Jordan C, Muccioli C, Vallochi AL, Rizzo LV, Belfort R Jr, Vitor RW, Silveira C, Sibley LD. Genetic divergence of Toxoplasma gondii strains associated with ocular toxoplasmosis, Brazil. Emerg Infect Dis. 2006;12:942-9.

140. Lehmann T, Marcet PL, Graham DH, Dahl ER, Dubey JP. Globalization and the population structure of Toxoplasma gondii. Proc Natl Acad Sci USA. 2006;103(30):11423-8.

141. - Minot S, Melo MB, Li F, Lu D, Niedelman W, Levine SS, Saeij JP. Admixture and recombination among Toxoplasma gondii lineages explain global genome diversity. Proc Natl Acad Sci USA. 2012;109(33):13458-63. Admixture and recombination of T. gondii lineages are responsible for most of the global genetic diversity of this parasite which causes some of the variation in manifestations of this infection.

142. Vaudaux JD, Muccioli C, James ER, et al. Identification of an atypical strain of Toxoplasma gondii as the cause of a waterborne outbreak of toxoplasmosis in Santa Isabel do Ivai. Brazil. J Infect Dis. 2010;202:1226-33.

143. Jamieson SE, de Roubaix LA, Cortina-Borja M, et al. Genetic and epigenetic factors at COL2A1 and ABC4 influence clinical outcome in congenital toxoplasmosis. PLoS ONE. 2008;3(6): e2285.

144. Jamieson SE, Cordell H, Petersen E, et al. Host genetic and epigenetic factors in toxoplasmosis. Mem Inst Oswaldo Cruz. 2009;104(2):162-9.

145. Jamieson SE, Peixoto-Rangel AL, Hargrave AC, et al. Evidence for associations between the purinergic receptor $\mathrm{P} 2 \mathrm{X}(7)$ (P2RX7) and toxoplasmosis. Genes Immun. 2010;11(5):374-83.

146. Lees MP, Fuller SJ, McLeod R, et al. P2X7 receptor-mediated killing of an intracellular parasite, Toxoplasma gondii, by human and murine macrophages. J Immunol. 2010;184(12):7040-6.

147. Mack DG, Johnson JJ, Roberts F, et al. HLA-class II genes modify outcome of Toxoplasma gondii infection. Int J Parasitol. 1999;29(9):1351-8.
148. Peyron F, Ateba AB, Wallon M, et al. Congenital toxoplasmosis in twins: a report of fourteen consecutive cases and a comparison with published data. Pediatr Infect Dis J. 2003;22:695-701.

149. • Witola WH, Mui E, Hargrave A, et al. NALP1 influences susceptibility to human congenital toxoplasmosis, proinflammatory cytokine response, and fate of Toxoplasma gondiiinfected monocytic cells. Infect Immun. 2011;79(2):756-66. NALP1 inflammasome influences susceptibility to human congenital toxoplasmosis and host cell death and cytokine production.

150. $\bullet$ Witola WH, Liu SR, Montpetit A, et al. ALOX12 in human toxoplasmosis. infect immun. 2014. [Epub ahead of print] In human toxoplasmosis, lipoxygenase 12 influences susceptibility to congenital toxoplasmosis. 12- HETE and 12 HPETE lead to release of pro-inflammatory cytokines and cell death which protects against this pathogen. They appear however to be capable of causing or contributing to diseases of neurodegeneration and atherosclerosis. This suggests that host defense mechanisms selected at child bearing age might contribute to disease of aging and neurodegneration.

151. Benenson MW, Takafuji ET, Lemon SM, Greenup RL, Sulzer AJ. Oocyst-transmitted toxoplasmosis associated with ingestion of contaminated water. $\mathrm{N}$ Engl J Med. 1982; 3007:666-9.

152. $\bullet$ Boyer K, Hill D, Mui E, et al. Unrecognized ingestion of Toxoplasma gondii oocysts leads to congenital toxoplasmosis and causes epidemics in North America. Clin Infect Dis. 2011;53(11):1081. Serum antibody to a sporozoite protein is present for approximately 6 months after acquisition. This was present in $70 \%$ of mothers of infants in the NCCCTS with only $20 \%$ recognizing possible cat exposure. This antibody was also present in family and water borne epidemics in North America.

153. Bowie WR, King AS, Werker DH, Isaac-Renton JL, Bell A, Eng SB, Marion SA. Outbreak of toxoplasmosis associated with municipal drinking water. The BC Toxoplasma Investigation Team. Lancet. 1997;350:173-7.

154. Dubey JP, Sharma SP, Juranek DD, Sulzer AJ, Teutsch SM. Characterization of Toxoplasma gondii isolates from an outbreak of toxoplasmosis in Atlanta. Georgia. Am $\mathbf{J}$ Vet Res. 1981;42(6):1007-10.

155. Frenkel JK, Dubey JP, Miller NL. Toxoplasma gondii in cats: fecal stages identified as coccidian oocysts. Science. 1970; 167(3919):893-6.

156. Frenkel JK, Parker BB. An apparent role of dogs in the transmission of Toxoplasma gondii. The probable importance of xenosmophilia. Ann N Y Acad Sci. 1996;791:402-7.

157. Fritz HM, Bowyer PW, Bogyo M, Conrad PA, Boothroyd JC. Proteomic analysis of fractionated Toxoplasma oocysts reveals clues to their environmental resistance. PLoS One. 2012;7(1): e29955.

158. - Hill D, Coss C, Dubey JP, et al. Identification of a sporozoitespecific antigen from Toxoplasma gondii. J Parasitol. 2011;97(2):328-37. Assay to detect antibody to sporozoite proteins of $T$. gondii in serum.

159. dos Santos TR, Nunes CM, Luvizotto MC, et al. Detection of Toxoplasma gondii oocysts in environmental samples from public schools. Vet Parasitol. 2010;171(1-2):53-7.

160. Lindsay DS, Collins MV, Mitchell SM, et al. Sporulation and survival of Toxoplasmosis gondii oocysts in seawater. J Eukaryot Microbiol. 2003;50:687-8.

161. Teutsch SM, Juranek DD, Sulzer A, Dubey JP, Sikes RK. Epidemic toxoplasmosis associated with infected cats. $\mathrm{N}$ Engl J Med. 1979;300:695-9.

162. Brown AS, Schaefer CA, Wuesenberry CP Jr, et al. Maternal exposure to toxoplasmosis and risk of schizophrenia in adult offspring. Am J Psychiatry. 2005;162:767-73. 
163. Henriquez SA, Brett R, Alexander J, Pratt J, Roberts CW. Neuropsychiatric disease and Toxoplasma gondii infection. NeuroImmunomodulation. 2009;16(2):122-33.

164. Hermes G, Ajioka JW, Kelly KA, et al. Neurological and behavioral abnormalities, ventricular dilatation, altered cellular functions, inflammation, and neuronal injury in brains of mice due to common, persistent, parasitic infection. J Neuroinflammation. 2008;5:48.

165. •• Wong WK, Upton A, Thomas MG. Neuropsychiatric symptoms are common in immunocompetent adult patients with Toxoplasma gondii acute lymphadenitis. Scand J Infect Dis. 2013;45(5):357-61. Neuropsychotic symptoms are part of postnatally acquired infections.

166. • Xiao J, Li Y, Prandovszky E, et al. MicroRNA-132 dysregulation in Toxoplasma gondii infection has implications for dopamine signaling pathway. Neuroscience. 2014;268:128-38. In mouse model microRNA-132 dysregulation in alters dopamine signaling.

167. Burnett AJ, Shortt SG, Isaac-Renton J, et al. Multiple cases of acquired toxoplasmosis retinitis presenting in an outbreak. Ophthalmology. 1998;105:1032-7.

168. Hogan MJ, Kimura SJ, Lewis A, Zweigart PA. Early and delayed ocular manifestations of congenital toxoplasmosis. Trans Am Ophthalmol Soc. 1957;55:275-96.

169. Holland GN, Crespi CM, ten Dam-van Loon N, et al. Analysis of recurrence patterns associated with toxoplasmic retinochoroiditis. Am J Ophthalmol. 2008;145:1007-13.

170. London NJ, Hovakimyan A, Cubillan LD, Siverio CD Jr, Cunningham ET Jr. Prevalence, clinical characteristics, and causes of vision loss in patients with ocular toxoplasmosis. Eur $\mathbf{J}$ Ophthalmol. 2011;21:811-9.

171. - Mansour AM, Mackensen F, Mahendradas P, Khairallah M, Lai TY, Bashshur Z. Five-year visual results of intravitreal bevacizumab in refractory inflammatory ocular neovascularization. Clin Ophthalmol. 2012;6:1233-7. Congenital toxoplasmosis in North America from 1981 to the present, and associated differences in manifestations of the infection in mother and child. Confirmation that alpha Veg $F$ treats choroidal neovacularization.

172. Silveira C, Belfort R Jr, Muccioli C, Holland GN, Victora CG, Horta BL, Yu F, Nussenblatt RB. The effect of long-term intermittent trimethoprim/sulfamethoxazole treatment on recurrences of toxoplasmic retinochoroiditis. Am J Ophthalmol. 2002;134(1):41-6.

173. Benevento JD, Jager RD, Noble AG, et al. Toxoplasmosisassociated neovascular lesions treated successfully with ranibizumab and antiparasitic therapy. Arch Ophthalmol. 2008;126:1152-6.

174. Capone A Jr. Treatment of neovascularization in infants with retinopathy of prematurity with anti-VEGF: vitreous surgery for retinopathy of prematurity. Paper presented at the annual meeting of the American Academy of Ophthalmology; Vegas, NV; 2006.

175. Yahia SB, Herbort CP, Jenzeri S, et al. Intravitreal bevacizumab (Avastin) as primary and rescue treatment for choroidal neovascularization secondary to ocular toxoplasmosis. Int Ophthalmol. 2008;28(4):311-6.

176. Derouin F, Almadany R, Chau F, Rouveix B, Pocidalo JJ. Synergistic activity of azithromycin and Pyrimethamine or Sulfadiazine in acute experimental toxoplasmosis. Antimicrob Agents Chemother. 1992;36(5):997-1001.

177. Derouin F. Anti-toxoplasmosis drugs. Curr Opin Investig Drugs. 2001;2(10):1368-74.

178. Eyles DE, Coleman N. An evaluation of the curative effects of Pyrimethamine and Sulfadiazine, alone and in combination, on experimental mouse toxoplasmosis. Antibiot Chemother. 1955;5:529-39.

179. Frenkel JK, Hitchings GH. Relative reversal by vitamins (pAminobenzoic, folic and folinic acid) of the effects of Sulfadiazine and Pyrimethamine on Toxoplasma, mouse and man. Antibiot Chemother. 1957;7:630-8.

180. • Doggett JS, Nilsen A, Forquer I, Wegmann KW, JonesBrando L, Yolken RH, Bordón C, Charman SA, Katneni K, Schultz T, Burrows JN, Hinrichs DJ, Meunier B, Carruthers VB, Riscoe MK. Endochin-like quinolones are highly efficacious against acute and latent experimental toxoplasmosis. Proc Natl Acad Sci USA. 2012;109(39):15936-41. Promise of definitive cure of $T$. gondii infections in brain with this compound targeting cytochrome $B C$ in mouse model.

181. •• Doggett JS, Ojo K, Fan E, Maly D, Van Voorhis W. Bumped kinase inhibitor 1294 treats established Toxoplasma gondii infection. Antimicrob Agents Chemother. [Epub ahead of print March 2014]. Cure of cysts in mouse model with Bump kinase inhibitor 1294.

182. Doliwa C, Escotte-binet S, Aubert D, et al. Sulfadiazine resistance in Toxoplasma gondii: no involvement of overexpression or polymorphisms in genes of therapeutic targets and $A B C$ transporters. Parasite. 2013;20:19.

183. Glasner PD, Silveira C, Kruszon-Moran D, Martins MC, Burnier Júnior M, Silveira S, Camargo ME, Nussenblatt RB, Kaslow RA, Belfort Júnior R. An unusually high prevalence of ocular toxoplasmosis in southern Brazil. Am J Ophthalmol. 1992; 114:136-44.

184. Grossman PL, Remington JS. The effect of trimethoprim and sulfamethoxazole on Toxoplasma gondii in vitro and in vivo. Am J Trop Med Hyg. 1979;28(3):445-55.

185. •• Lai BS, Witola WH, El Bissati K, Zhou Y, Mui E, Fomovska A, McLeod R. Molecular target validation, antimicrobial delivery, and potential treatment of Toxoplasma gondii infections. Proc Natl Acad Sci USA. 2012;109(35):14182-7. Molecular transporters linked to targeted anti-sense morpholinos provide promising approach to new treatments for toxoplasmosis.

186. - Lee Y, Choi JY, Fu H, Harvey C, Ravindran S, Roush WR, Boothroyd JC, Khosia C. Chemistry and biology of macrolide antiparasitic agents. J Med Chem. 2011;54(8):2792-804. Macrolide anti-T. gondii compound described.

187. Meneceur P, Bouldouyre MA, Aubert D, Villena I, Menotti J, Sauvage V, Garin JF, Derouin F. In vitro susceptibility of various genotypic strains of Toxoplasma gondii in Pyrimethamine, Sulfadiazine, and atovaquone. Antimicrob Agents Chemother. 2008;52(4):1269-77.

188. Mui EJ, Schiehser GA, Milhous WK, Hsu H, Roberts CW, Kirisits M, Muench S, Rice D, Dubey JP, Fowble JW, Rathod PK, Queener SF, Liu SR, Jacobus DP, McLeod R. Novel triazine JPC-2067-B inhibits Toxoplasma gondii in vitro and in vivo. PLoS Negl Trop Dis. 2008;2(3):e190.

189. Romand S, Pudney M, Derouin F. In vitro and in vivo activities of the hydroxynaphthoquinone atovaquone alone or combined with Pyrimethamine, Sulfadiazine, clarithromycin, or minocycline against Toxoplasma gondii. Antimicrob Agents Chemother. 1993;37(11):2371-8.

190. - Fomovska A, Wood RD, Mui E, Dubey JP, Ferreira LR, Hickman MR, Lee PJ, Leed SE, Auschwitz JM, Welsh WJ, Sommerville C, Woods S, Roberts CW, McLeod R. Salicylanilide inhibitors of Toxoplasma gondii. J Med Chem. 2012;55(19):8375-91 Potent new family of inhibitors of $T$. gondii effects in vitro in low nanomolar levels.

191. - Cong H, Mui EJ, Witola WH, Sidney J, Alexander J, Sette A, Maewal A, McLeod R. Towards an immunosense vaccine to 
prevent toxoplasmosis: protective Toxoplasma gondii epitopes restricted by HLA-A*0201. Vaccine. 2011a;29(4):754-62. Immunosense approach to creating $H L A$ A2 restricted peptides leads to vaccine protective against $T$. gondii infection in HLA A2 transgenic mice.

192. • Cong H, Mui EJ, Witola WH, Sidney J, Alexander J, Sette A, Maewal A, McLeod R. Human immunome, bioinformatic analyses using HLA supermotifs and the parasite genome, binding assays, studies of human $\mathrm{T}$ cell responses, and immunization of HLA-A*1101 transgenic mice including novel adjuvants provide a foundation for HLA-A03 restricted CD8+ T cell epitope based, adjuvanted vaccine protective against Toxoplasma gondii. Immunome.2011b; 6:12. All HLA mice can be protected by CD8+ peptides, a unusual CD4 peptide and GLA$S E$, and adjuvant.

193. - Cong H, Mui EJ, Witola WH, Sidney J, Alexander J, Sette A, Maewal A, El Bissati K, Zhou Y, Suzuki Y, Lee D, Woods S, Sommerville C, Henriquez FL, Roberts CW, McLeod R. Toxoplasma gondii HLA-B*702-restricted GRA7(20-28) peptide with adjuvants and universal helper $\mathrm{T}$ cell epitope elicits $\mathrm{CD} 8(+) \mathrm{T}$ cells producing interferon- $\gamma$ and reduces parasite burden in HLA-B*0702 mice. Hum Immunol. 2011b;73(1): 1-10. HLA B7 transgenic mice can be protected by CD8+ T cell HLA $B 7$ restricted peptides, with padre, with adjuvant.

194. Kaňková S, Sulc J, Křivohlavá R, Kuběna A, Flegr J. Slower postnatal motor development in infants of mothers with latent toxoplasmosis during the first 18 months of life. Early Hum Dev. 2012;88(11):879-84.

195. Tan TG, Mui E, Cong H, et al. Identification of T. gondii epitopes, adjuvants, and host genetic factors that influence protection of mice and humans. Vaccine. 2010;28(23):3977-89.

196. Lafferty KD. Can the common brain parasite, Toxoplasma gondii, influence human culture? Proc Biol Sci. 2006;273(1602): 2749-55.

197. Townsend JJ, Wolinsky JS, Baringer JR, Johnson PC. Acquired toxoplasmosis. A neglected cause of treatable nervous system disease. 1975;32(5):335-43.

198. - Mitra R, Sapolsky RM, Vyas A. Toxoplasma gondii infection induces dendritic retraction in basolateral amygdala accompanied by reduced corticosterone secretion. Dis Model Mech. 2012;6(2):516-20. T. gondii infection alters amygdala and reduces corticosterone secretion in mouse model.
199. • Kaushik M, Lamberton PH, Webster JP. The role of parasites and pathogens in influencing generalised anxiety and predationrelated fear in the mammalian central nervous system. Horm Behav. 2012;62(3):191-201. One of many studies which suggest but do not prove T. Gondii has a direct causal effect.

200. • Lavinsky D, Romano A, Muccioli C, Belfort R, Jr. Imaging in ocular toxoplasmosis. Int Ophthalmol Clin. 2012;52(4):131-43. Review of imaging techniques for ocular toxoplasmosis.

201. - Wang T, Zhou J, Gan X, et al. Toxoplasma gondii induce apoptosis of neural stem cells via endoplasmic reticulum stress pathway. Parasitology. 2012;141(7):988-95. T. gondii causes apoptosis of neural stem cells.

202. - Pfaff AW, De-la-torre A, Rochet E, et al. New clinical and experimental insights into Old World and neotropical ocular toxoplasmosis. Int J Parasitol. 2014;44(2):99-107. Ocular toxoplasmosis in new and old world.

203. - Sauer A, Rochet E, Lahmar I, et al. The local immune response to intraocular Toxoplasma re-challenge: less pathology and better parasite control through Treg/Th1/Th2 induction. Int J Parasitol. 2013;43(9):721-8.

204. - Collier SA, Stockman LJ, Hicks LA, Garrison LE, Zhou FJ, Beach MJ. Direct healthcare costs of selected diseases primarily or partially transmitted by water. Epidemiol Infect. 2012;140(11):2003-13. Toxoplasmosis causes substantial health care costs.

205. Hutson SL, Mui E, Kinsley K, Witola WH, Behnke MS, Bissati KE, Muench SP, Rohrman B, Liu SR, Wollmann R, Ogata Y, Sarkeshik A, Yates JR, McLeod R. T. gondii RP promoters and knockdown reveal molecular pathways associated with proliferation and cell-cycle arrest. PLoS One. 2010;5(11):e14057.

206. McLeod R, Lee D, Boyer K. Toxoplasmosis in the fetus and newborn infant. In: Stevenson DK, Sunshine P, Cohen RS, Van Meurs K, editors. Neonatology: clinical practice and procedural atlas. New York: McGraw-Hill; 2008.

207. McLeod R, Van Tubbergen C, Montoya J, Petersen E. Human toxoplasma infection. In: Weiss LM, Kim K, editors. Toxoplasma gondii: the model apicomplexan-perspectives and methods. vol. 2. London: Elsevier Press; 2014. p. 100-161.

208. Mehta V, Balachandran C, Lonikar V. Blueberry muffin baby: a pictoral differential diagnosis. Dermatol Online J. 2008;14(2):8. Retrieved from http://escholarship.org/uc/item/53q852nc. 